\title{
Modal and Dynamic Analysis of a Vehicle with Kinetic Dynamic Suspension System
}

\author{
Bangji Zhang, ${ }^{1}$ Jie Zhang, ${ }^{1}$ Jinhua Yi, ${ }^{2}$ Nong Zhang, ${ }^{1,3}$ and Qiutan Jin ${ }^{1}$ \\ ${ }^{1}$ State Key Laboratory of Advanced Design and Manufacturing for Vehicle Body, College of Mechanical and Vehicle Engineering, \\ Hunan University, Changsha, Hunan 410082, China \\ ${ }^{2}$ Guangzhou Automobile Group Co., Ltd., Automotive Engineering, Guangzhou, Guangdong 511434, China \\ ${ }^{3}$ School of Electrical, Mechanical and Mechatronic Systems, Faculty of Engineering and Information Technology, \\ University of Technology, Sydney, NSW 2007, Australia \\ Correspondence should be addressed to Jie Zhang; jiezhang1906@hnu.edu.cn
}

Received 24 February 2016; Revised 17 August 2016; Accepted 29 August 2016

Academic Editor: Emiliano Mucchi

Copyright (C) 2016 Bangji Zhang et al. This is an open access article distributed under the Creative Commons Attribution License, which permits unrestricted use, distribution, and reproduction in any medium, provided the original work is properly cited.

A novel kinetic dynamic suspension (KDS) system is presented for the cooperative control of the roll and warp motion modes of off-road vehicles. The proposed KDS system consists of two hydraulic cylinders acting on the antiroll bars. Hence, the antiroll bars are not completely replaced by the hydraulic system, but both systems are installed. In this paper, the vibration analysis in terms of natural frequencies of different motion modes in frequency domain for an off-road vehicle equipped with different configurable suspension systems is studied by using the modal analysis method. The dynamic responses of the vehicle with different configurable suspension systems are investigated under different road excitations and maneuvers. The results of the modal and dynamic analysis prove that the KDS system can reduce the roll and articulation motions of the off-road vehicle without adding extra bounce stiffness and deteriorating the ride comfort. Furthermore, the roll stiffness is increased and the warp stiffness is decreased by the KDS system, which could significantly enhance handing performance and off-road capability.

\section{Introduction}

Vehicle suspension system has always been considered as an essential component to alleviate the impact from road excitations to the vehicle body and to ensure the properties of comfortable driving, good handling, and safety of the vehicles [1-4]. Conventional suspension systems are often adopted by automobile manufacturers due to their cost effectiveness and reliabilities, but they are also confronted with the contradiction between handling performance and ride comfort. As is well known, the vehicle body motion caused by four wheels can be classified as four motion modes (bounce, pitch, roll, and warp modes) and these modes play a key role in analyzing the characteristics of the vehicles [57]. In general, the handling performance should possess stiff pitch and roll modes, but the soft bounce and warp modes are beneficial to the ride comfort $[8,9]$. Therefore, an advanced suspension system needs to be able to have both antiroll and road-holding abilities.
To date, many engineers have made great effort to improve the properties of vehicle suspensions. Advanced suspensions that include active suspensions and semiactive suspensions applied to luxury passenger cars have been proposed to balance the contradiction between vehicle ride comfort and handling performance. For manufactures, however, they are often faced with the inconvenience associated with these advanced suspensions, such as high cost, uncertain reliability, huge power consumption, and inherent complexity [10]. Therefore, in order to overcome the drawbacks of the above-mentioned conventional and advanced suspensions, novel passive suspension systems are being adopted in automotive industry. The interconnected suspension system is one of the most effective passive suspension systems that can eliminate the compromise between vehicle stability and ride performance. In contrast to conventional suspensions, interconnected suspensions not only are capable of uncoupling the four suspension modes (bounce, pitch, roll, and warp), but 
also have advantages in controlling stiffness and damping of each suspension mode. This kind of suspensions is achieved by the use of interconnections between the individual wheel stations and is realized through mechanical, hydraulic, or hydropneumatic means $[9,11-13]$, where the forces can be generated at other wheel stations when one wheel station of vehicles has the motion [5]. As a representative example, the passive hydraulically interconnected suspension (HIS) is realized through the use of the dynamic interconnection between the hydraulic circuits and the unsprung/sprung masses of vehicles. Furthermore, the conventional shock absorber is replaced by a single/double-acting hydraulic cylinder which is fixed at each wheel station. The chambers of hydraulic cylinders are interconnected by hydraulic circuits, and these elements (damper valves, hydraulic accumulators, pipelines, fittings, and flexible hoses) are the indispensable components for hydraulic circuits. When the vehicles are driven on the road, the sprung and unsprung masses must have the relative motion that makes fluid flow in the circuits of HIS systems. Due to the flow into or out of the accumulators, the volumes of accumulators are compressed or expanded and this leads to the changes of pressure in the hydraulic circuits. And the changes of pressure in the cylinder chambers make the restoring forces be applied to the suspension struts (the sprung and unsprung masses). HIS systems can obtain the desired levels of stiffness and damping by pushing flow into certain dampers and accumulators in order to reduce the motion of one given mode.

Compared to the conventional suspension systems, HIS systems have been paid only sporadic attention in the literature so far. In 1970s, the investigations on hydrolastic and hydragas systems were conducted by Moulton and Best [14]. The possible mechanical/hydraulic interconnections arrangements of four-wheel vehicle were conceptually presented by Ortiz, which could provide separate damping and springing for roll/warp or pitch/bounce modes [15]. Zapletal conceptually proposed the interconnected system to decouple the full vehicle modes, which is similar to Ortiz's system [16]. Mace introduced network theory and system synthesis methodologies to develop a theoretical study of existing passive HIS systems [17]. Furthermore, mechanical admittance matrices were employed to establish the mathematical model of this interconnected suspension, and the optimal handling and ride performances were achieved by adjusting the warp stiffness and damping levels of a linear full-car mode. Smith and Walker also applied this approach into a novel suspension concept, which could decouple the stiffness and damping of different modes [5]. From these mentioned studies, not only were most proposals of HIS systems purely conceptual and theoretical, but also the dynamics of the interconnecting mechanism were not investigated. Then, Behave conducted a parametric study of the influence of pneumatic pitch-plane interconnection arrangements on vehicle ride performance [18]. This study has shown that the optimum parameters (the flow loss coefficient, air spring volume to area ratio, vehicle mass, and mass distribution) could minimize the impact on the vibration transmissibility of the bounce and pitch modes caused by the road inputs. Compared with the reduction of the warp mode stiffness for unconnected system, the fully decoupled damping of HIS system could achieve better performance. An experimental investigation of the kinetic four-wheel HIS was presented to improve the handing performance by Wilde et al. [19]. The results implied that this system could provide higher roll stiffness than the conventional vehicle suspension systems. In recent years, the interconnected hydropneumatic suspensions in roll and pitch planes have been proposed by Cao [7, 20, 21]. They investigated the dynamic characteristics of this system at full-car level and the results showed that the ride and handling performances could be enhanced by adjusting the pitch stiffness and damping independently, particularly in heavy vehicle applications. Zhang and Smith have developed the research on the multibody system dynamics of vehicles fitted with HIS systems [22-24]. A systematic method was presented to investigate the mechanics of roll-plane HIS in time and frequency domain and the results were verified by the experiments. Ding et al. have presented a new HIS system to study the dynamics of triaxle heavy trucks [25]. The theoretical results showed that the proposed HIS system was able to reduce the pitch motion of sprung mass and maintain the ride comfort simultaneously. Nowadays, many researchers pay more attention to the investigation of the advantages of HIS system.

On the other hand, the antiroll bar is the most ubiquitous and simple interconnection arrangement in current application for conventional suspension systems. The antiroll bar provides higher stiffness to the roll and warp motion modes through a mechanical interconnection between left and right wheel-pairs, but the higher articulation stiffness is disadvantageous to ground holding performance. Thus, this antioppositional mechanism is unable to balance the contradiction between the roll and warp motions for vehicles. In addition, although the higher spring stiffness is beneficial to the handling performance, it will deteriorate the ride comfort. Therefore, conventional suspension systems with antiroll bars are incapable of solving the contradiction among ride comfort, handling performance, and ground holding performance. The semiactive or active suspension systems may have the ability to accomplish these functions, but it will be realized by high cost and huge power consumption. Considering the above-mentioned issues for antiroll bars and the advantages provided by HIS system, a novel kinetic dynamic suspension (KDS) system, which is a passive hydraulic system without consuming power, is proposed in this study to solve the contradiction among different performance requirements for off-road vehicles. The KDS system is realized through the hydraulic system and a particular mechanism. It is noteworthy that the KDS system consists of two hydraulic cylinders acting on the antiroll bars, and the antiroll bars are interconnected through the hydraulic system. Therefore, the antiroll bars are not completely replaced by the hydraulic system, but both systems are installed in order to coordinate the bounce, roll, and warp motion modes. To validate the effectiveness of the proposed KDS system, this paper presents the study about the characteristics of off-road vehicles fitted with KDS system in both frequency and time domains in terms of system modal analysis and dynamic responses under different conditions. It is seen from the numerical 


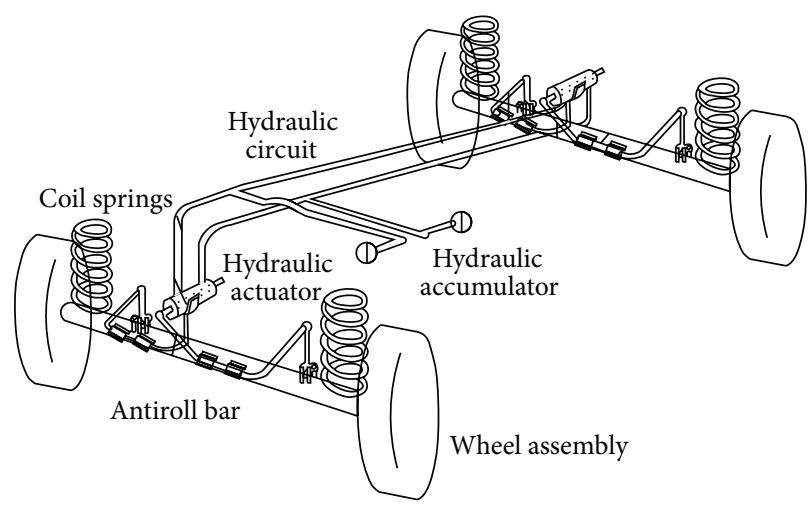

(a)

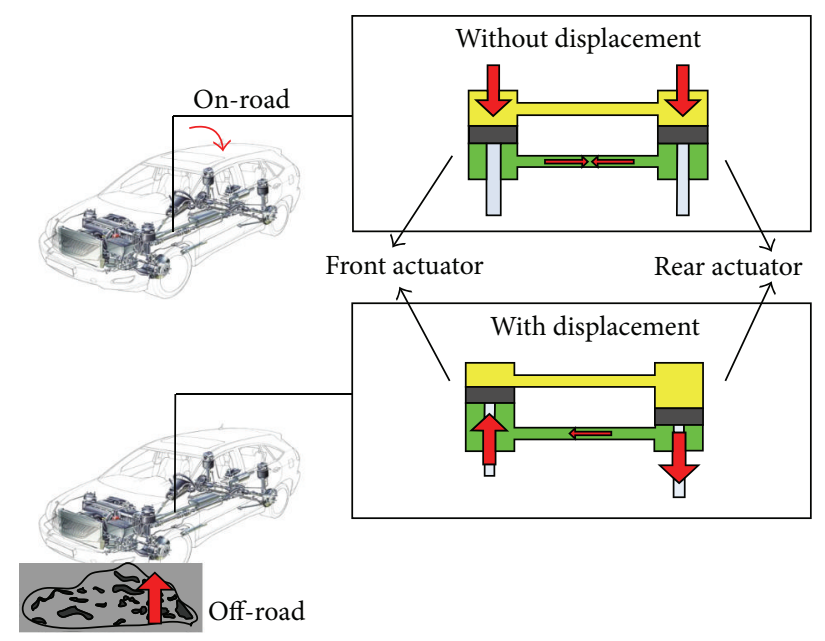

(b)

FIgURE 1: (a) A schematic layout of a two-axle vehicle with KDS system. (b) The working condition of a two-axle vehicle with KDS system.

results that the proposed KDS system can deliver higher roll mode stiffness than the conventional antiroll bar to improve handling performance and can reduce the warp mode stiffness to enhance ground holding performance compared to the conventional suspension system with antiroll bars. Furthermore, the KDS system does not add extra bounce stiffness and is able to maintain the ride comfort.

The remainder of the paper is organized as follows. Section 2 presents the system description of the KDS-equipped vehicle. The modelling of KDS-equipped vehicle is described in Section 3. The characteristic analysis of KDS system is presented in Section 4. Section 5 presents the comparative analysis of vehicles with the conventional suspension system and the proposed KDS system. Section 6 describes the discussions and future work, and the conclusions are drawn in Section 7.

\section{System Description of the KDS-Equipped Vehicle}

The schematic diagram of a two-axle vehicle with the KDS system is shown in Figure 1(a). The KDS-equipped vehicle system includes two subsystems: conventional vehicle system and hydraulic system (KDS system). The vehicle system consists of wheel assemblies, suspension systems (coil springs), and vehicle chassis. The car body is supported by the four-wheel assemblies. The coil springs are used to connect the vehicle chassis with wheel assemblies. Furthermore, coil springs can also support the chassis and alleviate the impact from road excitations to ensure ride comfort. The hydraulic system called KDS system comprises some hydraulic elements including two hydraulic actuators that can directly provide the forces between the vehicle body and wheel assemblies and hydraulic accumulators that can control the pressure of the hydraulic circuits, pipelines, hydraulic fittings, and flexible hoses. The KDS system together with antiroll bars and the hydraulically interconnected system are mounted at the front and rear parts of the vehicle. Antiroll bars are the simplest interconnection arrangement to reduce the roll motion and are fixed on the front and rear axles of vehicles. In Figure 1(a), antiroll bars are interconnected by means of the double-acting hydraulic actuator assemblies, which are different from the conventional antiroll bars. Each hydraulic actuator has a cylinder and a piston, and the cylinder is divided into the top chamber and bottom chamber. The cylinder is mounted at the end of one antiroll bar pair, while the piston is fixed at the end of the other antiroll bar pair. The chambers of the two actuator assemblies are interconnected by hydraulic circuits to provide the flow communication between chambers [26]. According to the aforementioned system description, the hydraulic cylinders are actually installed between the vehicle body and wheel assemblies through the antiroll bars. Furthermore, through the antiroll bars, the acting forces induced by the KDS system are imposed on them. Thus, the antiroll bars are not completely replaced by the hydraulic system but worked together through the hydraulic system.

According to Figure 1(a), the KDS system is a passive system without requiring external sensors to detect vehicle motions. During the cornering, the roll motion can result in an increase in pressure difference between the piston assemblies on one side of the vehicle and this can prevent the transfer of fluid between the connected fluid chambers and hold the cylinder pistons in place. Thus it can suppress the suspension stroke and ensure the suspension rigidity to reduce the roll motion of the vehicle. When the vehicle is driving off-road, the locations of the points where four wheels contact the ground are not all in the same plane. This leads to the compressing of the suspension of two diagonally opposed wheels, but the extending of the other two diagonally opposed wheels. The mode of suspension movement called warp motion can minimize the change of pressure difference between the piston assemblies to allow the flowing of fluid in the connected hydraulic circuits and to move the cylinder 
piston upwards and downwards. This is beneficial to extend the suspension stroke and a long suspension stroke helps the wheels contact with the ground. As shown in Figure 1(b), the KDS system can ensure the excellent performance for both on-road and off-road vehicles. However, modern vehicles with high center of gravity are normally equipped with the stiff antiroll bars in order to prevent the roll motion of the vehicle. A disadvantageous consequence of providing antiroll bars is that the ride quality is uncomfortable for passengers since two wheels of an axle are functionally interconnected in certain level, so the single wheel's inputs are not independent when the single wheel of vehicles travels on the bump or slope blocks.

\section{Modelling of KDS-Equipped Vehicle}

In this paper, a seven-degree-of-freedom (seven-DOF) fullcar model, which is often employed in the literature [27], is considered as the vehicle with conventional suspension system (VCS). The seven-DOF full-car model with KDS system shown in Figure 2 is defined as the vehicle with KDS system (VKDS) where the lumped sprung mass is $m_{s}$ and unsprung masses are $m_{u f}$ and $m_{u r}$. The lumped sprung mass of the vehicle model is considered to have three DOFs (bounce motion $z_{s}$ in the vertical direction, pitch motion $\theta$, and roll motion $\phi$ around the CG center (o) of the sprung mass), and each wheel has one DOF (bounce motion $z_{u f} / z_{u r}$ in the vertical direction). The front and rear suspension strut forces are applied at a fixed distance ( $a$ and $b$ ) from the $y$-axis and a fixed distance $\left(t_{f}\right.$ and $\left.t_{r}\right)$ from the $x$-axis. The suspensions are assumed to have the linear spring stiffness $\left(k_{s f} / k_{s r}\right)$ and damping coefficient $\left(c_{s f} / c_{s r}\right)$, and the vertical stiffness $\left(k_{t f} / k_{t r}\right)$ of the tyre is considered to be linear. In order to obtain the linear physical parameters for a two-axle vehicle, a new physical parameter identification method was proposed by Zheng et al., [28]. Based on the assumption of the linearity, they introduced the state variable method (SVM) to identify the modal parameter of the vehicle. Then, a known mass matrix was designed to add to the vehicle in order to make it possible to determine the mass, damping, and stiffness matrices of the vehicle. The purpose of this procedure is to increase the number of equations to ensure that the number of equations is more than one of the number of the unknown parameters. Consequently, the physical parameters of the two-axle vehicle, such as inertial parameters, stiffness, and damping, can be calculated by using least square method. According to the system description in Section 2, the only difference between the KDS-equipped vehicle system and the conventional suspension system is that the hydraulic system is installed on the conventional vehicle through the disconnected antiroll bars. Hence, the vehicle physical parameters of the KDSequipped vehicle system are the same as the vehicle with conventional suspension system and are given in Section 5.

According to Newton's second law and free-body diagrams of rigid bodies, the equations of the motion for the integrated mechanical-hydraulic system of the full-car model can be derived as

$$
M \ddot{Z}+C \dot{Z}+K Z=F_{\theta}+F_{e}(t),
$$

where $M, C$, and $K$ are the mass, damping, and stiffness matrices; $Z$ is the displacement vector; $F_{e}(t)$ is the road excitation force input matrix; $F_{\theta}=D_{1} K_{A R B} \theta_{A R B}$ describes the forces in the antiroll bars due to their torsion angles, where $K_{A R B}$ is the torsional stiffness matrix of antiroll bars; $\theta_{A R B}$ is the torsion angle of antiroll bars. The antiroll bar is a key component to transmit forces between the wheels/tyres and the chassis due to the torsion. $F_{i}(i=A, B, C, D)$ are the forces of four wheels caused by antiroll bars, and they are expressed in the following form:

$$
\begin{aligned}
& F_{i}=\frac{K_{i} \theta_{i}}{l_{1}} \quad(i=A, B), \\
& F_{m}=-\frac{K_{m} \theta_{m}}{l_{1}} \quad(m=C, D), \\
& Z=\left[\begin{array}{lllllll}
z_{S} & \theta & \phi & z_{u A} & z_{u B} & z_{u C} & z_{u D}
\end{array}\right]^{T} \text {, } \\
& \theta_{A R B}=\left[\begin{array}{llll}
\theta_{A} & \theta_{B} & \theta_{C} & \theta_{D}
\end{array}\right]^{T} \text {, } \\
& K_{A R B}=\operatorname{diag}\left[\begin{array}{llll}
K_{A} & K_{B} & K_{C} & K_{D}
\end{array}\right],
\end{aligned}
$$

where $l_{1}$ is the length of the outer arm of the front and rear antiroll bars; $K_{i}(i=A, B, C, D)$ are the torsional stiffness of the front and rear antiroll bars; $\theta_{i}(i=A, B, C, D)$ are the angles of the front and rear antiroll bars. According to Newton's third law, $F_{\theta}$ is the vector of the antiroll bar transmitting to the vehicle body; $D_{1}$ is the coefficient matrix. They are defined as the following form:

$$
\begin{aligned}
F_{\theta} & =D_{1} K_{A R B} \theta_{A R B} \\
& =\left[\begin{array}{c}
-F_{A}-F_{B}-F_{C}-F_{D} \\
-\left(F_{C}+F_{D}\right) * b+\left(F_{A}+F_{B}\right) * a \\
-\left(F_{A}-F_{B}\right) * t_{f}-\left(F_{c}-F_{D}\right) * t_{r} \\
\end{array}\right], \\
D_{1} & \frac{F_{A}}{l_{1}}\left[\begin{array}{cccc}
-1 & F_{B} \\
-1 & & & F_{C} \\
a & a & b & b \\
-t_{f} & t_{f} & t_{r} & -t_{r} \\
1 & 0 & 0 & 0 \\
0 & 1 & 0 & 0 \\
0 & 0 & -1 & 0 \\
0 & 0 & 0 & -1
\end{array}\right] .
\end{aligned}
$$

3.1. Model of Antiroll Bars. Antiroll bars connect the left and right wheels, which are commonly used for the suspension system to increase roll stiffness and to reduce the roll motion of the vehicle. Due to the fact that the antiroll bars only work in roll motion of vehicles, the equations of motion of the front 


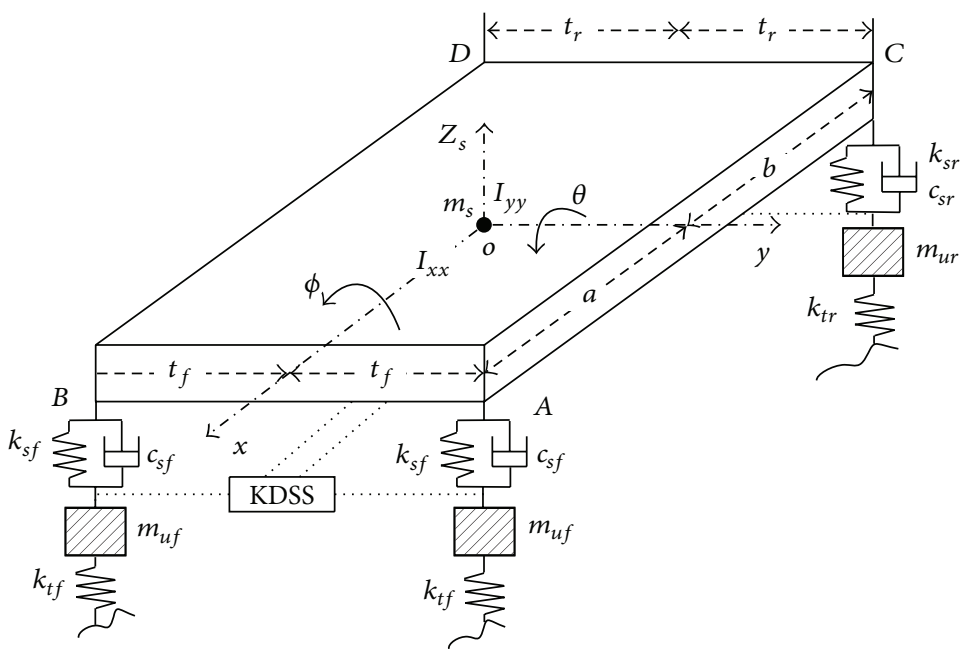

FIgURE 2: Schematic of a 7-DOF two-axle vehicle model with KDS system.

and rear antiroll bar models are described in the following form based on Newton's second law:

$$
I_{A R B} \ddot{\theta}_{A R B}+K_{A R B} \theta_{A R B}=F_{P}+F_{T},
$$

where $I_{A R B}$ and $K_{A R B}$ are the inertia and stiffness matrices of the antiroll bar, respectively; $F_{T}=-D_{1}^{T} K_{A R B} X$ describes the force matrix of the antiroll bar induced by the suspension system. The force matrix $F_{P}$ of the antiroll bar due to the pressure in the cylinder chambers is written as $F_{P}=D_{2} A P(t)$, where the area matrix $A$ and pressure vector $P$ related to the corresponding cylinder chambers are defined as $P(t)=$ $\left[\begin{array}{llll}P_{f t} & P_{f b} & P_{r t} & P_{r b}\end{array}\right]^{T}$ and $A=\operatorname{diag}\left[\begin{array}{llll}A_{f t} & A_{f b} & A_{r t} & A_{r b}\end{array}\right]$, and the coefficient matrix $D_{2}$ is defined as the following form:

$$
D_{2}=\left[\begin{array}{cccc}
-l_{2} & l_{2} & 0 & 0 \\
l_{2} & -l_{2} & 0 & 0 \\
0 & 0 & -l_{2} & l_{2} \\
0 & 0 & l_{2} & -l_{2}
\end{array}\right] \text {, }
$$

where $l_{2}$ is the length of the inner arm of the antiroll bars acting on hydraulic actuators. Combining (1) and (4), the equations of motion for the completely integrated vehicleKDS system can be given by

$$
\widehat{M} \ddot{Y}+\widehat{C} \dot{Y}+\widehat{K} Y=\widehat{F}_{P}+\widehat{F}_{e},
$$

where

$$
\begin{aligned}
\widehat{M} & =\left[\begin{array}{cc}
M & O \\
O & I_{A R B}
\end{array}\right]_{11 \times 11}, \\
\widehat{C} & =\left[\begin{array}{cc}
C & O_{7 \times 4} \\
O_{4 \times 7} & O_{4 \times 4}
\end{array}\right]_{11 \times 11}, \\
\widehat{K} & =\left[\begin{array}{cc}
K & -D_{1} K_{A R B} \\
D_{1}^{T} K_{A R B} & K_{A R B}
\end{array}\right]_{11 \times 11},
\end{aligned}
$$
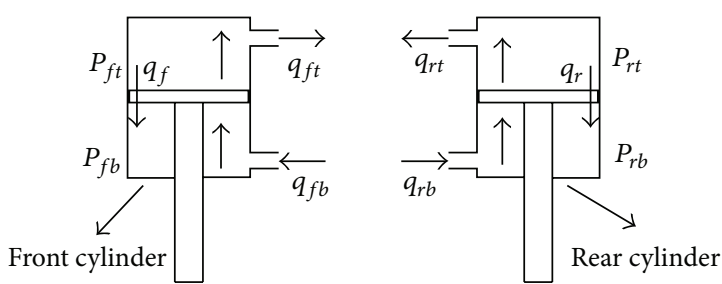

FIGURE 3: Mechanical-fluid system boundary conditions.

$$
\begin{aligned}
& \widehat{F}_{P}=D_{3} A P(t)=\left[\begin{array}{c}
0_{7 \times 4} \\
D_{2}
\end{array}\right] A P(t), \\
& \widehat{F}_{e}=\left[\begin{array}{c}
F_{e}(t) \\
O_{4 \times 1}
\end{array}\right]_{11 \times 1} .
\end{aligned}
$$

The state vector of the integrated system is defined as $Y=\left[\begin{array}{ll}Z^{T} & \theta_{A R B}^{T}\end{array}\right]^{T}$. Furthermore, the original mass, damping, and stiffness matrices from (1) are modified into $\widehat{M}, \widehat{C}$, and $\widehat{K}$ by adding the effects relating to the antiroll bars, and $\widehat{F}_{P}$ describes the nonlinear coupling effect between the mechanical and hydraulic subsystems.

3.2. Model of the Mechanical-Fluid System. Figure 3 shows the double-acting hydraulic cylinders fixed on the antiroll bars in the new KDS-equipped vehicle system. From Figure 3, the piston divides the cylinder into the top and bottom chambers to form the boundary within the mechanical-fluid system. The relative velocity between the ends of the piston rod results in a boundary fluid flow towards/away from the hydraulic lines. Thus, the volume and pressure in the top and bottom chambers change correspondingly. Based on the well-known relationship of fluid compressibility, the fluid compressibility 
in the top and bottom chambers $q_{\operatorname{comp}(t)}$ and $q_{\operatorname{comp}(b)}$ is described as

$$
\begin{aligned}
q_{\text {comp }(f t)} & =\dot{z}_{s u f} A_{f t}-q_{f}-q_{f t}(t) \\
& =\frac{V_{f t}^{0}-z_{s u f} A_{f t}}{E} \dot{P}_{f t}(t), \\
q_{\text {comp }(f b)} & =q_{f b}(t)-\left(\dot{z}_{s u f} A_{f t}-q_{f}\right) \\
& =\frac{V_{f b}^{0}+z_{s u f} A_{f b}}{E} \dot{P}_{f b}(t), \\
q_{\text {comp }(r t)} & =\dot{z}_{s u r} A_{r t}-q_{r}-q_{r t}(t) \\
& =\frac{V_{r t}^{0}-z_{s u r} A_{r t}}{E} \dot{P}_{r t}(t), \\
q_{\text {comp }(r b)} & =q_{r b}(t)-\left(\dot{z}_{s u r} A_{r t}-q_{r}\right) \\
& =\frac{V_{r b}^{0}+z_{s u r} A_{r b}}{E} \dot{P}_{r b}(t),
\end{aligned}
$$

where $E$ is the bulk modulus of the cylinder chamber; $q_{i}(i=$ $f t, r t)$ and $q_{j}(j=f b, r b)$ denote the outflow and inflow of the top and bottom chambers of the front and rear hydraulic cylinders, respectively; $V_{i}^{0}$ and $V_{j}^{0}$ are the original volumes of the top and bottom chambers. $q_{f}$ and $q_{r}$ are the cross-line leakage flows due to the pressure differential in each piston and are given by the leakage coefficients, $H_{f}$ and $H_{r}$. They are defined as the following forms:

$$
\begin{aligned}
& q_{f}=\frac{\left(P_{f t}-P_{f b}\right)}{H_{f}}, \\
& q_{r}=\frac{\left(P_{r t}-P_{r b}\right)}{H_{r}} .
\end{aligned}
$$

Assume the small roll motion of the vehicle and the relative velocity of the piston rods of the front and rear cylinders $\dot{z}_{\text {suf }}$ and $\dot{z}_{\text {sur }}$ are given by

$$
\begin{aligned}
& \dot{z}_{s u f}=l_{2}\left(-\dot{\theta}_{2}-\dot{\theta}_{1}\right)+\frac{l_{2}}{l_{1}\left[\dot{z}_{u A}-\dot{z}_{s A}-\left(\dot{z}_{u B}-\dot{z}_{s B}\right)\right]}, \\
& \dot{z}_{s u r}=l_{2}\left(-\dot{\theta}_{3}-\dot{\theta}_{4}\right)+\frac{l_{2}}{l_{1}\left[\dot{z}_{u C}-\dot{z}_{s C}-\left(\dot{z}_{u D}-\dot{z}_{s D}\right)\right]}
\end{aligned}
$$

When (9) and (10) are applied to (8), the flow vector $Q(t)=\left[\begin{array}{llll}q_{f t} & q_{f b} & q_{r t} & q_{r b}\end{array}\right]^{T}$ can be written in the following form:

$$
Q(t)=D_{4} A \dot{Y}(t)+H P(t)+\widetilde{V}(t) \dot{P}(t),
$$

where $D_{4}$ is a constant linear transformation matrix; $H$ is the leakage flow resistance matrix; $\widetilde{V}(t)$ is a time-variant matrix of cylinder volume and bulk modulus terms.

In order to investigate the motion properties of the mechanical-fluid coupled system in (6), the fluid system equation $Q=f(P)$ describing the relationship between the flow and the pressure is employed. The hydraulic impedance method is proposed for the frequency domain modelling due to its computational advantages in this paper. Moreover, this method has been used to study the modal characteristics for triaxle trucks with HIS by Ding et al., [25]. The equation of the fluid system is given as follows:

$$
Q(s)=R(s)^{-1} P(s),
$$

where $R(s)$ is the impedance matrix of the fluid system elements. Furthermore, based on (12), the Laplace transform of (11) with zero initial conditions is written as

$$
\begin{gathered}
s P(s)=\widetilde{V}(s)^{-1}\left(R(s)^{-1}-H\right) P(s) \\
-s \widetilde{V}(s)^{-1} D_{4} A Y(s) .
\end{gathered}
$$

Equation (6) describes the motion for the integrated mechanical-hydraulic system. According to the Laplace transform (13), (6) can be rewritten as

$$
s^{2} \widehat{M} Y(s)+s \widehat{C} Y(s)+\widehat{K} Y(s)=D_{3} A P(s)+\widehat{F}_{e}(s) \text {. }
$$

In this section, $u=\left[\begin{array}{lll}Y(t) & P(t)\end{array}\right]^{T}$ is defined as the coupled system state vector. According to the state space method, the motion equation can be given by combining (13) with (14):

$$
s U(s)=\widehat{A}(s) U(s)+B N(s),
$$

where $U(s)$ is the Laplace transform of the state vector $u$ and $N$ is the Laplace transform of the vector of applied nonsuspension forces; $\widehat{A}(s)$ is the system characteristic matrix, and $B$ is the road disturbance input matrix. They are described in the following form:

$$
\begin{aligned}
& \widehat{A}(s) \\
& =\left[\begin{array}{ccc}
O & I & O \\
\widehat{M}^{-1} \widehat{K} & \widehat{M}^{-1} \widehat{C} & \widehat{M}^{-1} D_{3} A \\
O & \widetilde{V}^{-1}(s) D_{4} A & \widetilde{V}^{-1}(s)\left(R^{-1}(s)-H\right)
\end{array}\right], \\
& B=\left[\begin{array}{c}
O \\
\widehat{M}^{-1} \\
O
\end{array}\right], \\
& N(s)=\widehat{F}_{e}(s) .
\end{aligned}
$$

Equation (15) represents the general equation of motion for the completely integrated system in frequency domain. In order to study the modal characteristics, this paper needs to obtain the solutions of the aforementioned equations through numerical iterative approach. Before solving the equations of the coupled system, it can be seen that the calculation of the system characteristic matrix $\widehat{A}(s)$ is not an easy task due to the impedance matrix $R(s)$. The impedance matrix depends on the precise arrangement of the hydraulically interconnected system which includes the fluid circuits and the individual components. The details for the determination of the impedance matrix have been shown in the literature [22]. 
3.3. Dynamic Equations of Mechanical-Fluid System. This section mainly describes the dynamic model which includes the state space representation of the integrated full-car system for the transient analysis. The details of the derivation of dynamic equations of the coupled vehicle multibody system and hydraulic circuits by the state space method for transient analysis can be found in the literature [23,29]. According to the description of the coupled system in the aforementioned sections, the state vector that describes the motion of the sprung and unsprung lumped multibody model is defined as the following form:

$$
X_{M}=\left[\begin{array}{llll}
Z^{T} & \dot{Z}^{T} & \theta_{A R B}^{T} & \dot{\theta}_{A R B}^{T}
\end{array}\right]^{T} .
$$

The state vector that describes the dynamic states of the hydraulic subsystem is given by the following form:

$$
\begin{aligned}
& X_{H} \\
& \quad=\left[\begin{array}{llllllllll}
P_{f t} & P_{f r} & P_{r t} & P_{r b} & P_{a 1} & P_{a 2} & q_{f t} & q_{f r} & q_{r t} & q_{r r}
\end{array}\right]^{T},
\end{aligned}
$$

where $P_{a 1}, P_{a 2}$ describe the pressures of the two hydraulic accumulators. Furthermore, $X=\left[\begin{array}{ll}X_{M}^{T} & X_{H}^{T}\end{array}\right]^{T}$ is defined as the state vector of the coupled mechanical-fluid system by integrating the two state vectors $X_{M}$ and $X_{H}$ together.

Based on the free-body diagram approach and Newton's second law, the state space equation of the full-car system is derived as the following form:

$$
T \dot{X}=G X+F .
$$

Thus, (19) can be written in the following form:

$$
\begin{gathered}
{\left[\begin{array}{ccccc}
I_{7} & 0 & 0 & 0 & 0 \\
0 & M_{7} & 0 & 0 & 0 \\
0 & 0 & I_{4} & 0 & 0 \\
0 & 0 & 0 & I_{A R B} & 0 \\
0 & 0 & 0 & 0 & T_{H}
\end{array}\right]_{32 \times 32}\left[\begin{array}{c}
\dot{Z} \\
\ddot{Z} \\
\dot{\theta}_{A R B} \\
\ddot{\theta}_{A R B} \\
\dot{X}_{H}
\end{array}\right]_{32 \times 1}} \\
=\left[\begin{array}{ccccc}
0 & I_{7} & 0 & 0 & 0 \\
-K & -C & 0 & 0 & 0 \\
0 & 0 & 0 & I_{4} & 0 \\
0 & 0 & G_{L} & 0 & 0 \\
0 & 0 & 0 & 0 & S_{H}
\end{array}\right]_{32 \times 32}\left[\begin{array}{c}
Z \\
\dot{Z} \\
\theta_{A R B} \\
\dot{\theta}_{A R B} \\
X_{H}
\end{array}\right]_{32 \times 1} \\
+\left[\begin{array}{c}
0 \\
F_{V} \\
0 \\
F_{L} \\
F_{H}
\end{array}\right]_{32 \times 1}
\end{gathered}
$$

According to the aforementioned study of the coupled system, it is noted that the external forces $F_{V}, F_{L}$, and
$F_{H}$ include interactive elements between mechanical and hydraulic systems. They can be described as

$$
\begin{gathered}
F_{V}=D_{1} K_{A R B} \theta_{A R B}+F_{e}(t), \\
F_{L}=G_{H L} X_{H}-D_{1}^{T} K_{A R B} Z, \\
F_{H}=K_{H Z} Z+C_{H Z} \dot{Z}+F_{h},
\end{gathered}
$$

where $G_{L}, G_{H L}, K_{H Z}$, and $C_{H Z}$ are the linear coefficients matrices relating to the motions of the mechanical system and dynamics of the suspension fluid circuits; $T_{H}$ and $S_{H}$ are the linear coefficient matrices of the fluid circuits; $F_{h}$ describes the nonlinear effects on the fluid system.

In order to study the dynamic behaviors of the vehicle fitted with the KDS system, the dynamic state of the multibody system and the fluid system can be determined simultaneously by using the first 22 equations of the multibody system and the last 10 equations of the fluid system. Furthermore, a fourth-order Runge-Kutta numerical integration method is used to obtain the solutions of differential equation (19).

\section{Characteristic Analysis of KDS System}

The hydraulic layout of the KDS system including two identical fluid circuits is shown in Figure 4. The two identical double-acting piston-cylinder actuators, which are fixed at the front and rear antiroll bars, are coupled with each other kinetically through the two hydraulic pipelines, hydraulic accumulators and hydraulic fittings. During the vehicle cornering, the roll motion can result in the long displacement of suspensions $B$ and D and the short displacement of suspensions A and C. Due to the movements of four suspensions, the hydraulic oil in circuit B flows into accumulator B while the hydraulic oil in circuit A flows out from accumulator A. The gas of accumulator B is compressed and the gas of accumulator $A$ is released which can result in the pressure of hydraulic circuit B rising and the pressure of hydraulic circuit A falling. The generated hydraulic force coupled through the antiroll bars acts against the vehicle body roll motion. The restoring roll moments of the KDS system $\left(M_{\mathrm{KDS}}\right)$ and conventional suspension system $\left(M_{\mathrm{CS}}\right)$ can be expressed as

$$
\begin{aligned}
M_{\mathrm{KDS}} & =M_{\text {spring }}+M_{h}, \\
M_{\mathrm{CS}} & =M_{\text {spring }}+M_{\text {Anti-roll }},
\end{aligned}
$$

where $M_{\text {spring }}$ is the restoring roll moment developed due to restoring forces of springs; $M_{\text {Anti-roll }}$ is the restoring roll moment of the conventional antiroll bars; $M_{h}$ is the restoring roll moment developed due to the restoring hydraulic force and is written as

$$
\begin{aligned}
M_{h}= & 2 n\left(p_{f t} A_{f t}-p_{f b} A_{f b}\right) t_{f} \\
& +2 n\left(p_{r t} A_{r t}-p_{r b} A_{r b}\right) t_{r},
\end{aligned}
$$

where $n$ is the lever ratio related to $l_{1}$ and $l_{2}$ of the disconnected antiroll bars. Due to the nonlinear change of oil pressures for two hydraulic circuits, $M_{h}$ can be significantly larger 


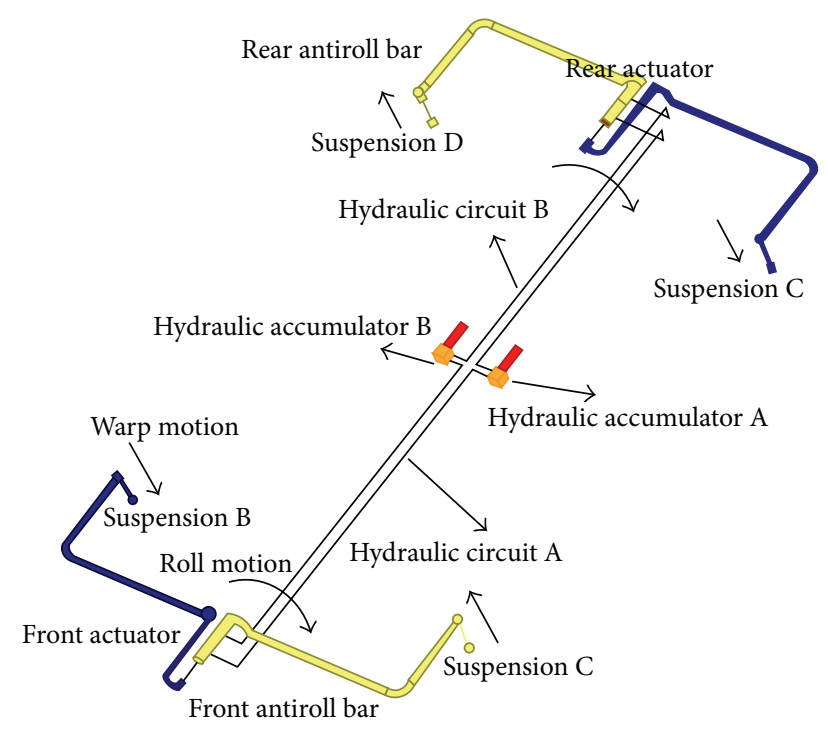

FIGURE 4: Three-dimensional diagram of a KDS system.

than $M_{\text {Anti-roll }}$. Hence, the roll stiffness of the KDS system is higher than the conventional suspension system, and the KDS system has the ability to enhance handing performance.

When the vehicle is driving off-road, the locations of four wheels contacting the ground are not all in the same plane. As is shown in Figure 4, suspensions $\mathrm{A}$ and $\mathrm{D}$ of two diagonally opposed wheels are compressed and suspensions B and C of the other two diagonally opposed wheels are extended. For the KDS system, the hydraulic oil in the top chamber of the front actuator flows into the top chamber of the rear actuator through circuit $\mathrm{A}$ and there is no oil flowing into/out accumulator A. Furthermore, the hydraulic oil in the bottom chamber of the rear actuator flows into the rear chamber of the front actuator through circuit $\mathrm{B}$ and there is no oil flowing into/out accumulator B. Hence, the oil pressures of the two hydraulic circuits A and B are unable to be changed. In the warp motion, the vehicle body twisting moments of the KDS system $\left(T_{\mathrm{KDS}}\right)$ and conventional suspension system $\left(T_{\mathrm{CS}}\right)$ can be expressed as

$$
\begin{aligned}
T_{\mathrm{KDS}} & =T_{\text {spring }}+T_{h}, \\
T_{\mathrm{CS}} & =T_{\text {spring }}+T_{\text {Anti-roll }},
\end{aligned}
$$

where $T_{\text {spring }}$ is the twisting moment of the vehicle body due to restoring forces of springs; $T_{\text {Anti-roll }}$ is the restoring roll moment of the vehicle body due to the conventional antiroll bars; $T_{h}$ is the twisting moment of the vehicle body due to the restoring hydraulic force and is written as

$$
T_{H}=\left(F_{H A} t_{f}-F_{H B} t_{f}\right)+\left(F_{H D} t_{r}-F_{H C} t_{r}\right),
$$

where $F_{H i}(i=A, B, C, D)$ are the hydraulic forces acting on the vehicle body through the disconnected antiroll bars. They can be expressed as

$$
\begin{aligned}
& F_{H A}=-F_{H B}=n\left(p_{f t} A_{f t}-p_{f b} A_{f b}\right), \\
& F_{H D}=-F_{H C}=n\left(p_{r t} A_{r t}-p_{r b} A_{r b}\right) .
\end{aligned}
$$

Because of the invariability of oil pressures, the twisting moment $T_{h}$ due to the restoring hydraulic force is very small. But, the twisting moment $T_{\text {Anti-roll }}$ is usually larger due to the limitation of conventional antiroll bars in the warp motion. Thus, the KDS system has the ability to provide smaller twisting moment than conventional suspension system. In the warp motion, the smaller twisting moment is beneficial to the vehicle body, but the larger twisting moment is able to damage the vehicle body. Due to the oil free flow in hydraulic circuits, the suspension movements in the warp motion cannot be restricted. Therefore, the KDS system has the ability to improve ground holding performance and keep the balance of the body attitude in the warp motion.

\section{Numerical Analysis}

In this section, the comparative analysis of vehicles with the conventional suspension system and the proposed KDS system is shown. The comparison is done about both the modal characteristic and the dynamic response. The physical parameters of a seven-DOF vehicle model, which can be identified by the physical parameter identification method [28], are shown in the Parameters. The Parameters also lists the hydraulic parameters of the KDS system based on the literature [23]. The solutions of the motion equations are obtained according to the vehicle parameters and the appropriate numerical method.

5.1. Modal Analysis of Mechanical-Fluid System. According to Section 3, it is obvious that the frequency-dependent coefficient $\hat{A}(s)$ is the system modal characteristic matrix and this matrix is changed with the input frequency $s$. According to the definition of eigenvalue, the solutions of the equation $|\operatorname{det}(\widehat{A}(s)-s I)|=0$ are the eigenvalues of $\widehat{A}(s)$. Since the exact eigenvalues of $\widehat{A}(s)$ are difficult to obtain numerically, approximate roots are acceptable if the function $W(s)=$ $|\operatorname{det}(\widehat{A}(s)-s I)|$ is approaching a minimum value in the vicinity of $s$. Based on this theory, the Matlab optimization library function fminsearh is employed to determine the real eigenvalues from the local minimum values.

A three-dimensional plot of the function $W(s)$ with respect to the real and imaginary parts of $s$ shows clearly that the modulus of the determinant reaches a minimum value at the eigenfrequency. The logarithm value $W(s)$ in Figure 5 is used to evaluate the numerical solutions under the given frequency range. It can be seen that the numerical value of the vertical axis can theoretically obtain the infinitesimal value, but this depends on the changes of parameters and the computer accuracy.

According to the numerical solution of modal equations in Section 3.2, the identified eigenvalues and eigenvectors, the natural frequencies, and the free vibration mode shapes are shown in Table 1 . The results in Table 1 show that the first three mode shapes involve the bounce, roll, and pitch motions of the sprung mass, and the next four mode shapes are related to the wheel hop motions for the VKDS and VCS. Compared with VCS, the KDS system can effectively increase the roll mode (the 2 nd mode) frequency of the sprung mass vibration 
TABLE 1: Natural frequencies and mode shape comparison.

\begin{tabular}{|c|c|c|c|c|c|c|c|}
\hline & \multicolumn{7}{|c|}{ Mode shape } \\
\hline & 1st & 2nd & $3 \mathrm{rd}$ & 4 th & 5 th & 6 th & 7 th \\
\hline \multicolumn{8}{|c|}{ VCS } \\
\hline$f(\mathrm{~Hz})$ & 1.493 & 1.528 & 1.842 & 9.837 & 10.110 & 10.211 & 10.552 \\
\hline$\xi$ & 0.340 & 0.240 & 0.334 & 0.219 & 0.207 & 0.250 & 0.239 \\
\hline$Z_{s}$ & 1 & 0 & $0.560-0.210 i$ & $-0.016+0.050 i$ & 0 & $-0.024+0.060 i$ & 0 \\
\hline$\theta$ & $-0.390+0.110 i$ & 0 & 1 & $-0.023+0.060 i$ & 0 & $0.012-0.050 i$ & 0 \\
\hline$\varphi$ & 1 & 1 & 0 & 0 & $0.048-0.060 i$ & 0 & $0.023+0.090 i$ \\
\hline$Z_{\mu A}$ & $0.011-0.080 i$ & $0.058-0.036 i$ & $-0.030+0.060 i$ & $-0.030-0.068 i$ & $-0.030-0.020 i$ & 1 & -1 \\
\hline$Z_{\mu B}$ & $0.011-0.080 i$ & $-0.058+0.036 i$ & $-0.030+0.060 i$ & $-0.030-0.068 i$ & $0.030+0.020 i$ & 1 & 1 \\
\hline$Z_{\mu \mathrm{C}}$ & $0.025-0.040 i$ & $0.052-0.027 i$ & $0.190-0.130 i$ & 1 & -1 & $0.024+0.060 i$ & $0.024+0.063 i$ \\
\hline$Z_{\mu D}$ & $0.025-0.040 i$ & $-0.052+0.027 i$ & $0.190-0.130 i$ & 1 & 1 & $0.024+0.060 i$ & $-0.024-0.063 i$ \\
\hline \multicolumn{8}{|c|}{ VKDS } \\
\hline$f(\mathrm{~Hz})$ & 1.492 & 1.689 & 1.840 & 9.040 & 9.840 & 9.930 & 10.210 \\
\hline$\xi$ & 0.346 & 0.350 & 0.330 & 0.396 & 0.225 & 0.215 & 0.257 \\
\hline$Z_{s}$ & 1 & 0 & $-0.390+0.110 i$ & $0.110+0.080 i$ & $0.110+0.080 i$ & $0.030+0.040 i$ & $0.030+0.040 i$ \\
\hline$\theta$ & $0.560-0.210 i$ & 0 & 1 & $0.002+0.080 i$ & $-0.002-0.080 i$ & $-0.020-0.080 i$ & $0.020+0.080 i$ \\
\hline$\varphi$ & 0 & 1 & 0 & $-0.030-0.070 i$ & $-0.030-0.070 i$ & $0.190+0.130 i$ & $0.190+0.130 i$ \\
\hline$Z_{\mu \mathrm{A}}$ & 0 & 0 & $-0.210-0.410 i$ & 1 & -1 & $-0.810-0.160 i$ & $0.810+0.160 i$ \\
\hline$Z_{\mu B}$ & $-0.016-0.050 i$ & $-0.023-0.060 i$ & 0 & $-0.030+0.070 i$ & $-0.030+0.070 i$ & 1 & 1 \\
\hline$Z_{\mu \mathrm{C}}$ & 0 & 0 & $0.050-0.004 i$ & $-0.870-0.230 i$ & $0.870+0.230 i$ & -1 & 1 \\
\hline$Z_{\mu D}$ & $-0.024-0.060 i$ & $0.012+0.050 i$ & 0 & 1 & 1 & $0.0240-0.060 i$ & $0.024-0.060 i$ \\
\hline
\end{tabular}

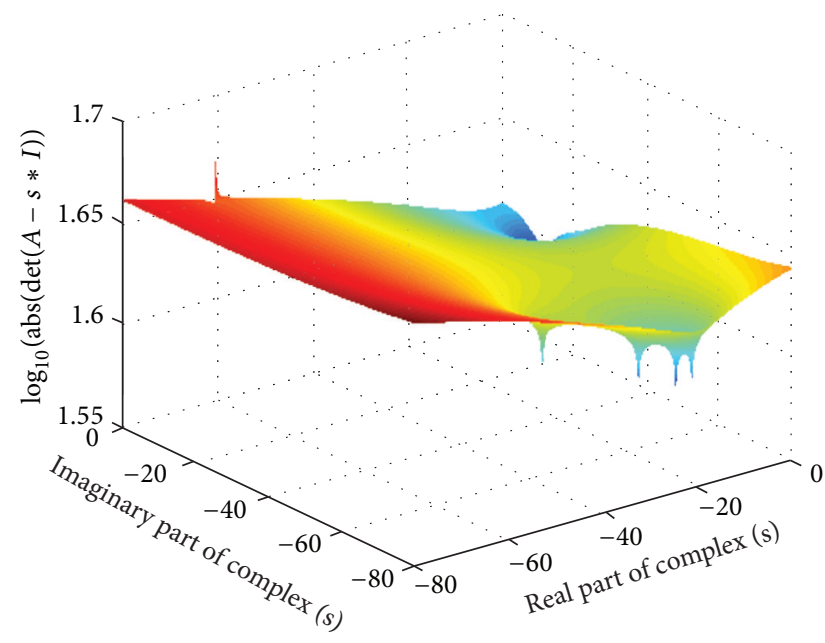

Figure 5: Three-dimensional diagram of $\log (\operatorname{abs}(W(s)))$.

(from $1.528 \mathrm{~Hz}$ to $1.689 \mathrm{~Hz}$ ) and maintain the bounce and pitch modes (the 1st and 3rd modes) frequencies of the sprung mass vibration (from 1.493 and $1.842 \mathrm{~Hz}$ to 1.492 and $1.840 \mathrm{~Hz}$ ). Furthermore, it can reduce the natural frequencies of the warp and oppositional hops between the left and right wheels (from 10.552 and $10.110 \mathrm{~Hz}$ to 9.040 and $9.930 \mathrm{~Hz}$ ) and hold the natural frequencies of oppositional and synchronous hops between the front and rear wheels (from 9.837 and $10.211 \mathrm{~Hz}$ to 9.840 and $10.210 \mathrm{~Hz}$ ). The KDS system can simultaneously increase the damping ratios corresponding to the roll and warp modes of the integrated system.
Based on the analytical results of mode shapes, the KDS system is able to provide higher stiffness of the roll mode to improve the handing performance and also provides softer stiffness of the warp mode to improve ground holding performance. Moreover, the KDS system does not change the stiffness of the bounce and pitch modes and hence guarantees the ride comfort.

5.2. Dynamic Response. This section introduces the timedomain response of the full-car model to validate the advantages of the KDS system to an off-road vehicle under excitations of lateral acceleration and road inputs. In the following actual driving scenarios, the roll/warp and bounce motions of the VKDS and VCS are compared to investigate the vehicles performance.

5.2.1. Roll Motion. It is well known that roll motion is important for the handling performance and too severe roll motion may make the vehicle out of control. The handling performance is defined as the percentage of the available friction or the maximum achievable lateral acceleration according to Harty [30]. When the centrifugal force that a vehicle experiences during cornering exceeds the available friction force, sliding or yaw motions of the vehicle may occur. This section investigates the well-known slalom test and fishhook maneuver of the VKDS and VCS. The equivalent roll moments of the vehicle body induced by these two tests are applied to the full-car model. Figures 6(a) and 6(b) show these two equivalent lateral acceleration inputs as a function of time. 


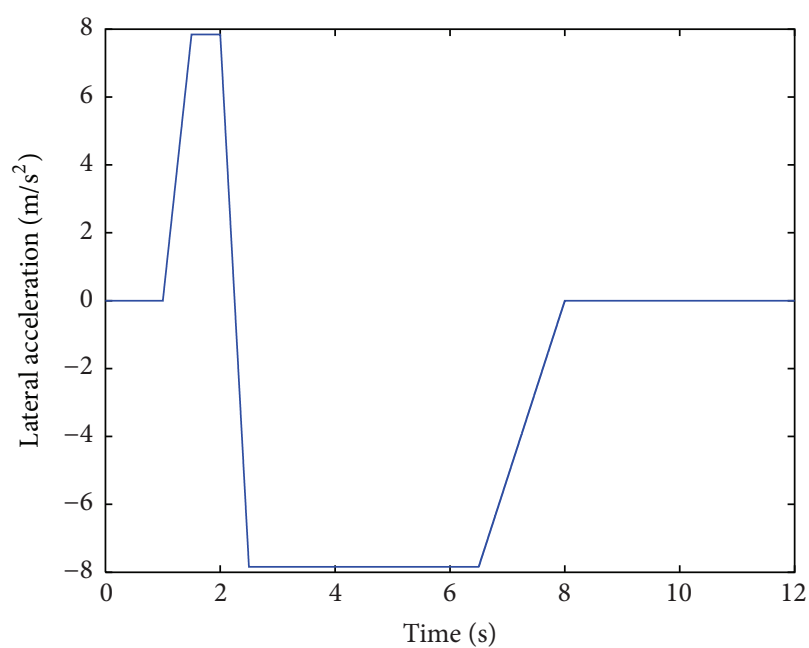

(a)

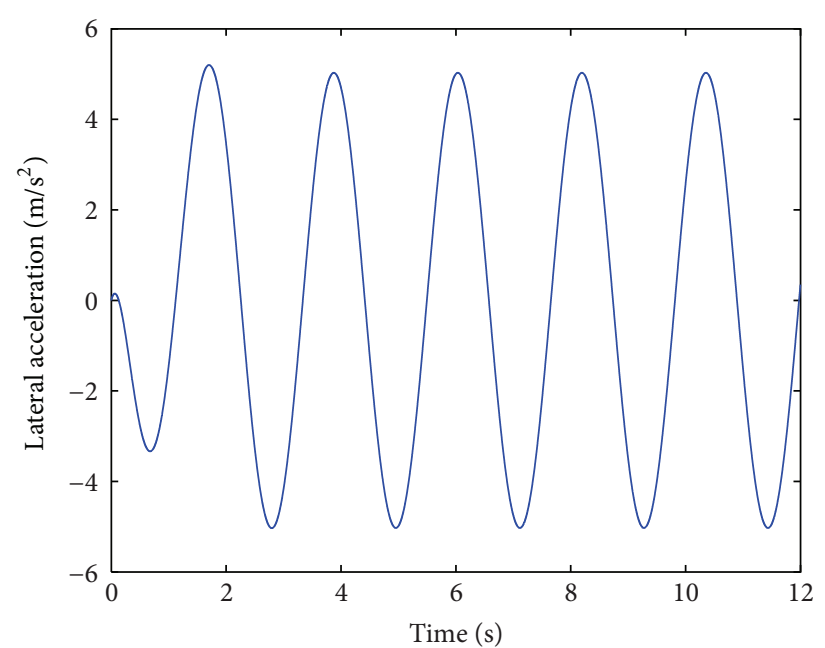

(b)

Figure 6: (a) Equivalent lateral acceleration of the fishhook maneuver. (b) Equivalent lateral acceleration of the slalom test.

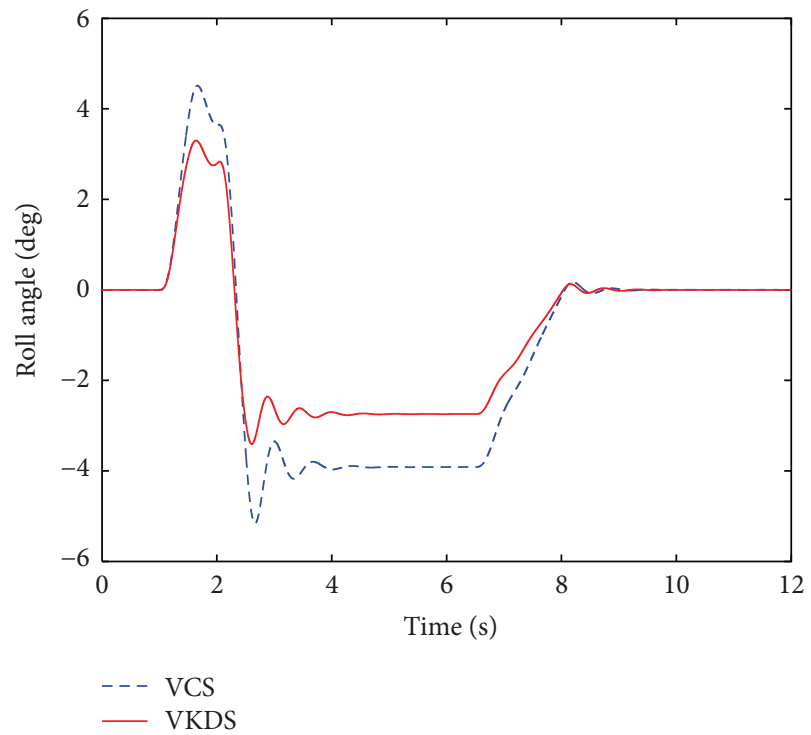

(a)

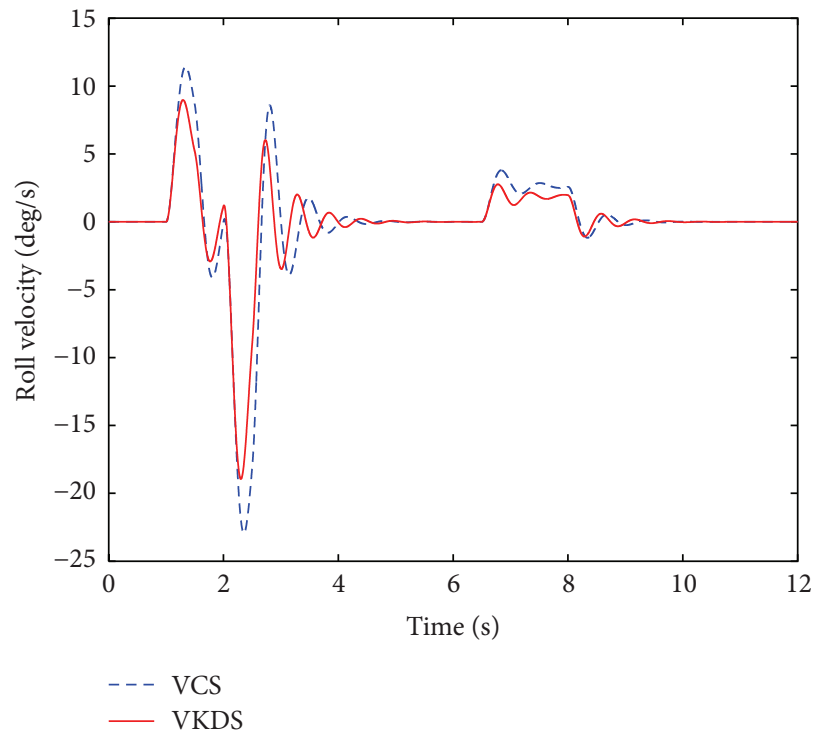

(b)

FIgURE 7: (a) Sprung mass roll angle of the VCS and VKDS under the fishhook maneuver. (b) Sprung mass roll velocity.

Figures $7(\mathrm{a}), 7(\mathrm{~b}), 8(\mathrm{a})$, and $8(\mathrm{~b})$ compare sprung mass roll angles and velocity responses of the vehicle models with two suspension configurations (VKDS and VCS) under the simulations of the slalom test and fishhook maneuver given in Figures 6(a) and 6(b). In these tests, both the sprung mass roll angle and velocity are used to describe the handling performance. The designed stiffness of the antiroll bar is defined as the minimum target value so that the roll stiffness of KDS system is not less than the value of antiroll bar. It can be clearly seen from Figures 7(a), 7(b), 8(a), and 8(b) that the VKDS experiences a significantly smaller roll angle and velocity. According to the formula $f_{\text {roll }}=\sqrt{k_{\text {roll }} / I_{\text {roll }}} / 2 \pi\left(f_{\text {roll }}\right.$ is the roll oscillation frequency, $k_{\text {roll }}$ is the roll mode stiffness, and $I_{\text {roll }}$ is the roll moment inertia of the sprung mass), the higher roll mode stiffness of the VKDS is also verified from the relatively higher oscillation frequency of the roll mode compared to the VCS (from $1.528 \mathrm{~Hz}$ to $1.689 \mathrm{~Hz}$ ) in Table 1. Furthermore, the results show that the roll velocity responses of the VKDS decay faster than the VCS, which is attributed to the enhanced roll mode damping properties of the KDS system, and the higher roll mode damping has the ability to ensure the balance of the body attitude in short time.

Figures 9(a) and 9(b) illustrate the comparisons of sprung mass roll angle responses of the VKDS with different oil pressures ( $20 \mathrm{bar}, 30 \mathrm{bar}$, and $40 \mathrm{bar}$ ) in this set of simulations. The results indicate that the sprung mass roll angle of the VKDS with the 40-bar oil pressure is smaller than the value of the antiroll bar, but the roll angle in the 20-bar oil pressure 


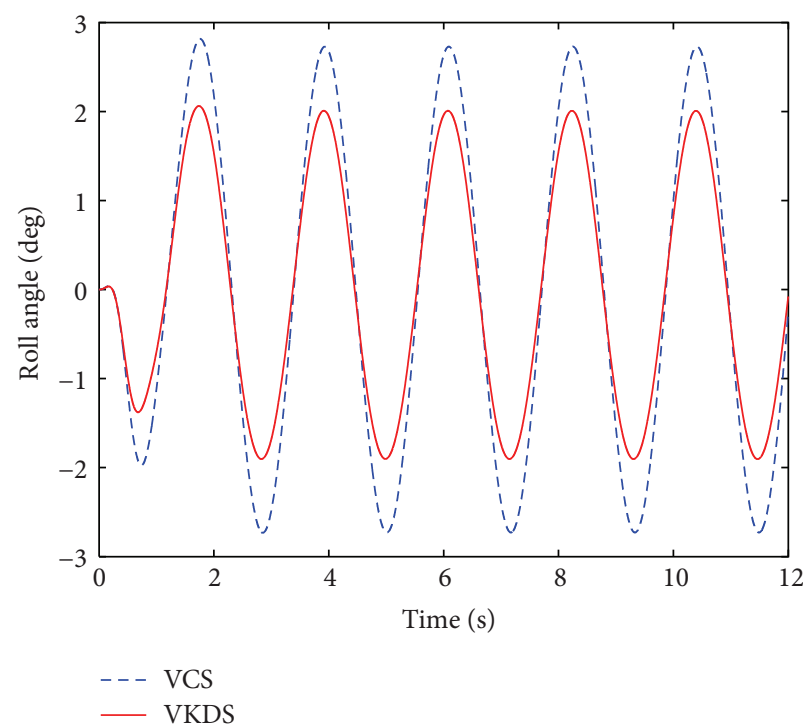

(a)

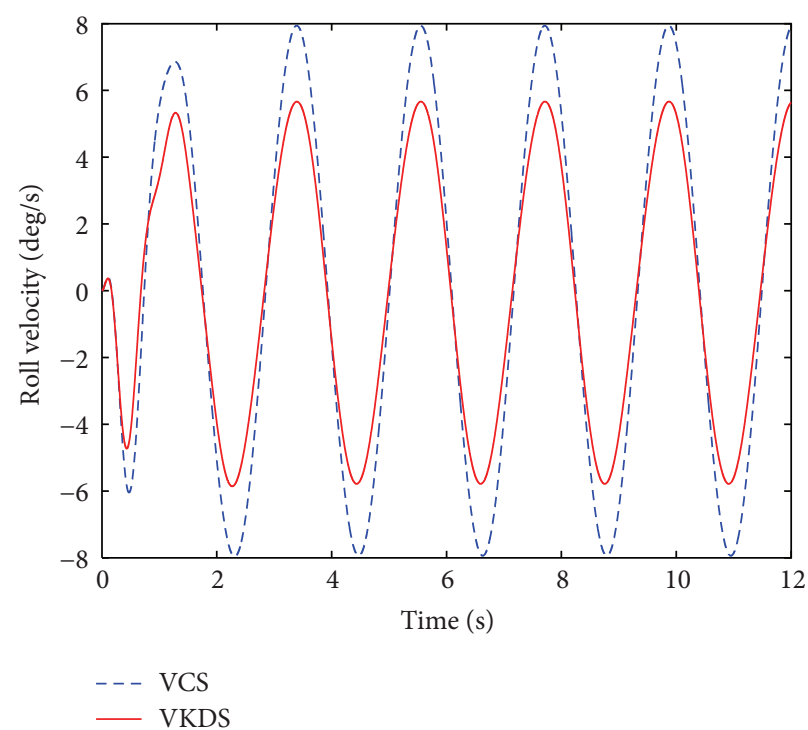

(b)

FIGURE 8: (a) Sprung mass roll angle of the VCS and VKDS under the slalom test. (b) Sprung mass roll velocity.

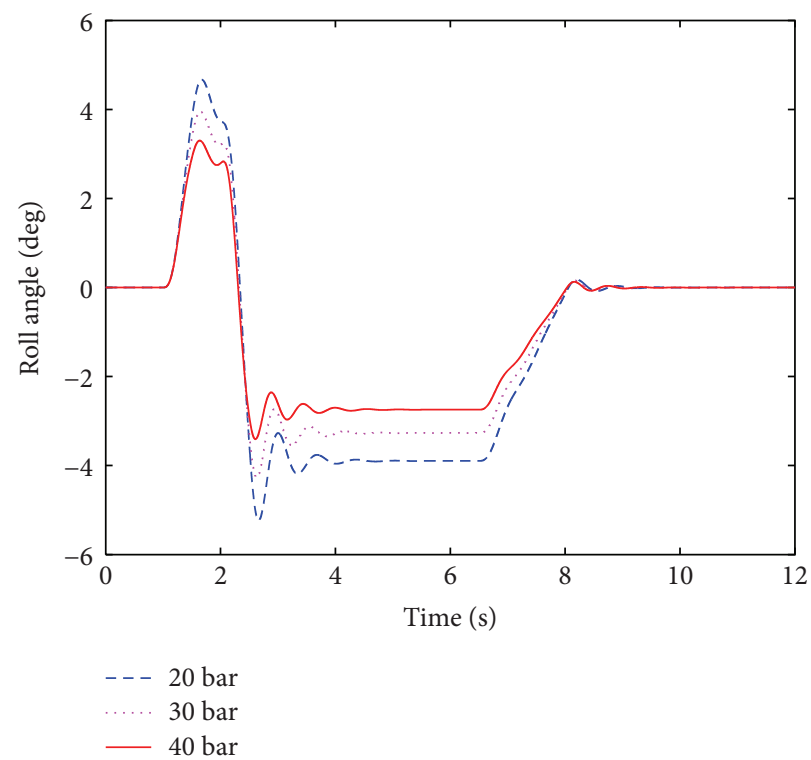

(a)

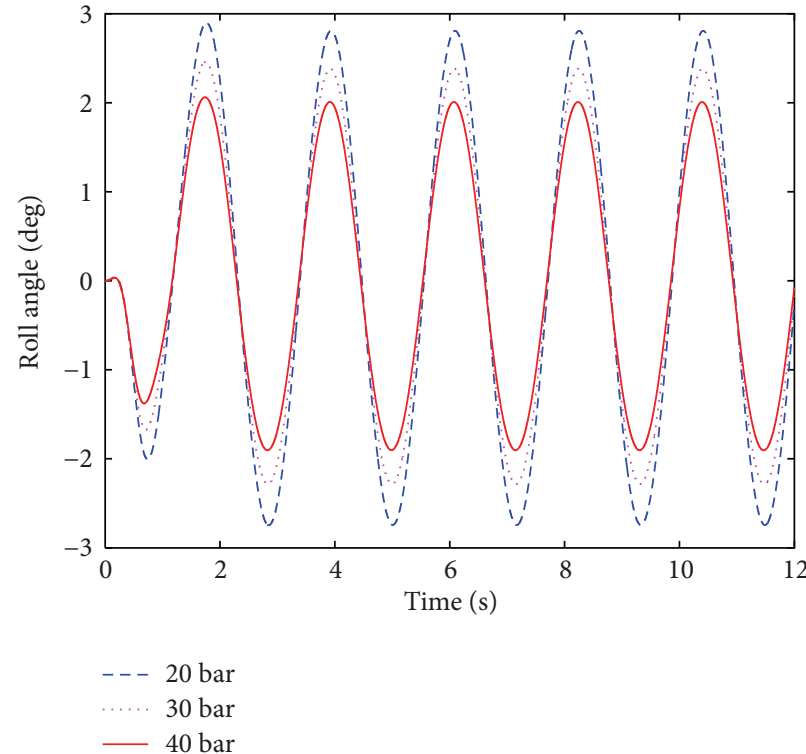

(b)

FIGURE 9: (a) Sprung mass roll angle of the VKDS with different oil pressures under the fishhook maneuver. (b) Sprung mass roll angle of the VKDS with different oil pressures under the slalom test.

condition is nearly identical to the value of antiroll bar. Compared with the antiroll bars, the passive KDS system could automatically generate fluidic mass flows into/out of the actuators so that the oil pressures of the top and bottom chambers of hydraulic actuators change rapidly to generate the reacting forces to control relative roll displacement between the sprung mass and the unsprung masses. It can be seen that higher oil pressure is able to provide the higher roll stiffness to prevent roll motion of the off-road vehicles.
5.2.2. Warp Motion. For off-road vehicles, a stiff warp mode is harmful to the handling performance and chassis structure. When off-road vehicles are driven on the rugged road, four vehicle wheels are not all in a single plane as shown in Figure 10. A stiff warp mode can worsen the uneven weight distribution of the four wheels and constrain the relative motion of the wheels, which may lead to the lifting up of a wheel on the rugged road. The lift of driving wheels and steering wheels has the negative impact on forward driving 


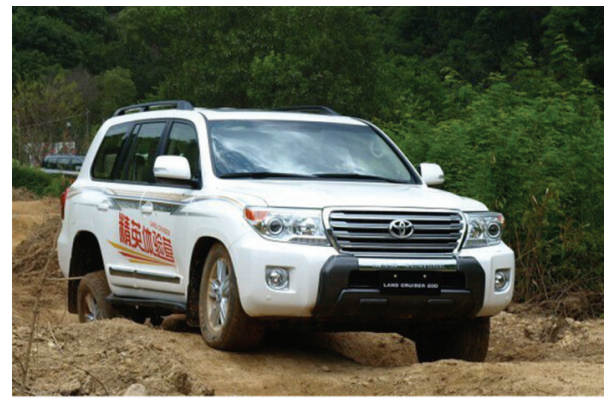

FIGURE 10: The warp mode excitation.

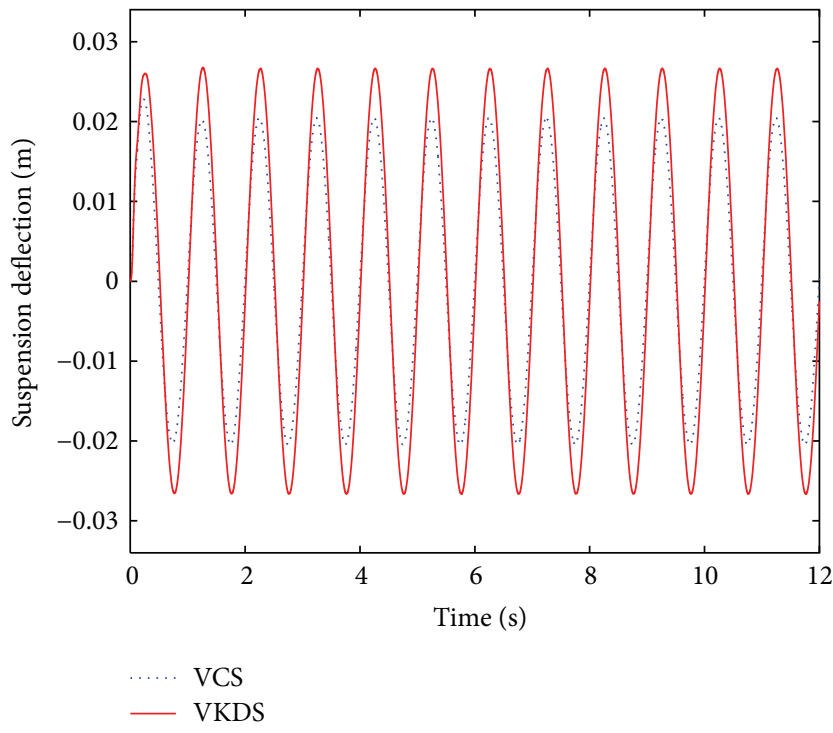

(a)

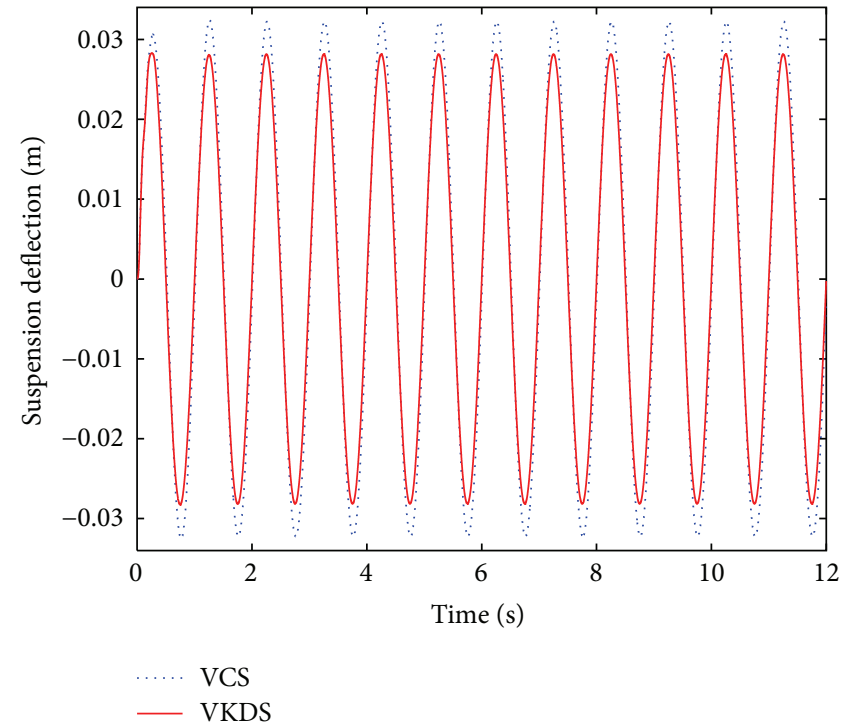

(b)

FIGURE 11: (a) Vehicle suspension deflection of the VCS and VKDS in front left station. (b) In rear right wheel station.

torque, steering, and handling performance. Furthermore, the too large twist torque can damage the chassis due to a pair of roll moments. The directions of this pair of roll moments are opposite to each other, which leads to twist vehicle chassis along $x$-axis. Thus, this motion of the four wheels is defined as the warp mode.

The antiroll bars are normally applied to connect the wheels of the front and rear axles of off-road vehicles to increase roll stiffness, but they can result in the stiff warp mode. Compared with the antiroll bars, the KDS system interconnects the front and rear wheels, and it cannot afford the additional stiffness to the warp mode. When the left wheels' inputs are opposite to the right wheels, the antiroll bars can generate the antiroll forces exerted on the vehicle body to prevent roll motion. When two diagonally opposed wheels' inputs are opposite to the other two diagonally opposed wheels as shown in Figure 10, they could twist vehicle chassis along $x$-axis.
The warp mode is excited by uneven ground and it can impact the handling performance at low frequency, and this road excitation is defined by the following equation:

$$
z_{g i}(t)=A_{i} \sin (2 \pi f t),
$$

where $A_{A}=-A_{B}=-A_{C}=A_{D}=0.03 \mathrm{~m}$ and $f=1 \mathrm{~Hz}$.

Figures 11(a) and 11(b) show the comparisons of the front left and the rear right suspension deflections of the vehicle models with two suspension configurations (VKDS and VCS) under the warp mode excitation. The off-road vehicles are normally equipped with the front and rear antiroll bars, and the front antiroll bar generally contributes to the major roll stiffness of the vehicles. The results show that the front left suspension deflection of the VCS is smaller than the VKDS due to the installation of the conventional front antiroll bar. When the road excitation is applied to the front wheels, the front antiroll bar could push the full vehicle body rotating due to the vehicle major roll stiffness induced by the front 


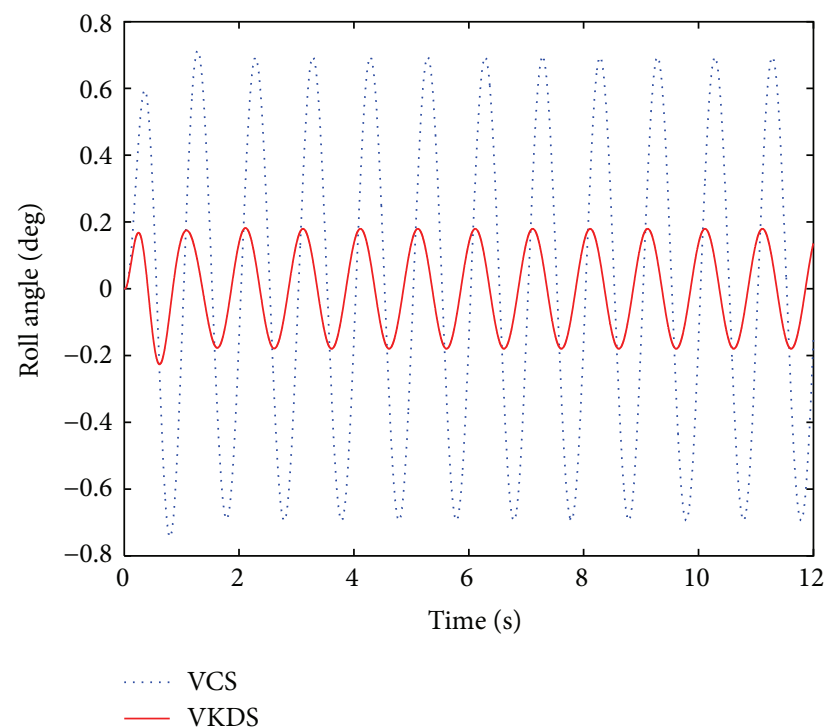

(a)

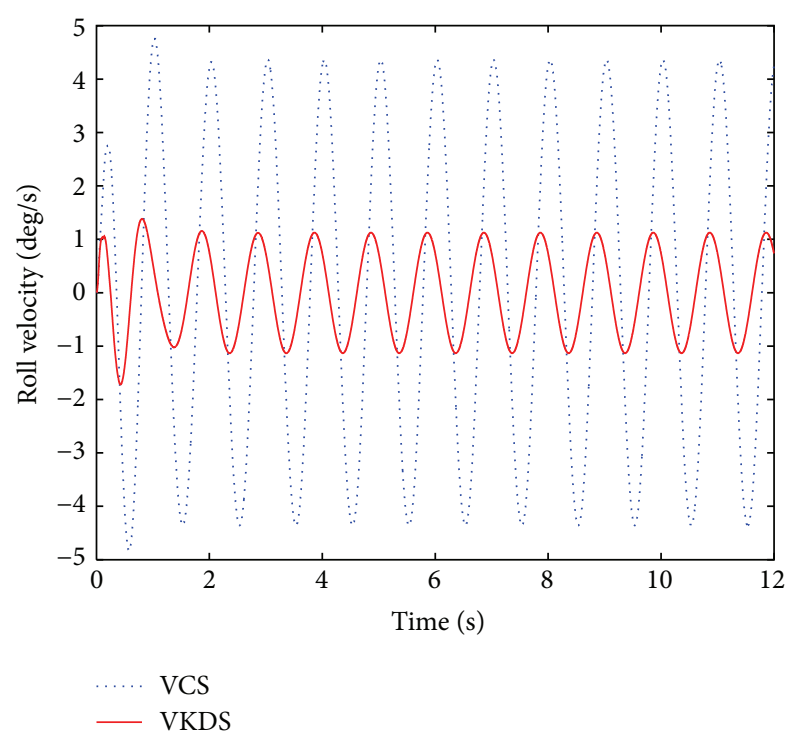

(b)

FIGURE 12: (a) Sprung mass roll angle of the VCS and VKDS under the warp mode excitation. (b) Sprung mass roll velocity.

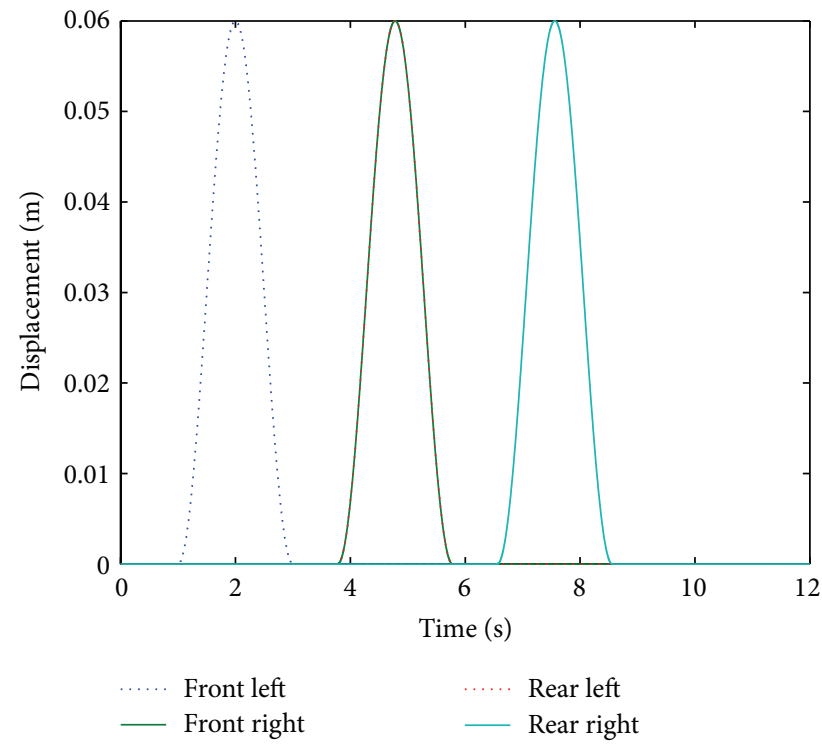

FIGURE 13: The road inputs of four wheels.

antiroll bar. The vehicle body motion resists the rear wheels' motion, which can increase the rear right wheel's suspension deflection of the VCS. In this case, the rear right wheel's suspension deflection of the VKDS is smaller than the VCS due to the oil free flow in hydraulic circuits. The results also illustrate that the twisting moment of the vehicle body for the VCS is larger than the VKDS in the warp mode. Thus, this means that the conventional antiroll bars heavily put the vehicle loads on two diagonally opposed wheels where the coil springs are already compressed, but the other two diagonally opposed wheels have the tendency to lift up in order to further diminish the normal forces. Thus, the conventional antiroll bars could worsen the vehicle roadholding performance under the warp motion.

Figures 12(a) and 12(b) illustrate the comparisons of sprung mass roll angle and velocity responses of the VKDS and VCS. Vehicle body roll mode motion is also excited under warp excitation due to the stiffness difference of the front and rear suspensions. The results show that the vehicle body roll angle and velocity are noticeably lower for the vehicle equipped with KDS system which decouples the roll and warp modes and has no negative effect on the warp mode. From Table 1, it can be seen that the natural frequency $9.040 \mathrm{~Hz}$ of VKDS is smaller than $10.552 \mathrm{~Hz}$ of VCS in warp mode. This means that the warp stiffness of VKDS is softer than VCS. These results in time and frequency domain can validate the performance of KDS system.

In order to further test the system performance, the typical bump road profile $z_{g}$ is used to simulate the warp inputs. The ground displacement for an isolated bump in an otherwise smooth road surface can be expressed as

$$
z_{g}(t)= \begin{cases}0 & t<1 \\ \frac{H}{2}\left[1-\cos \left(\frac{2 \pi v_{0}}{l} t\right)\right] & 1 \leq t \leq \frac{l}{v} \\ 0 & t>\frac{l}{v},\end{cases}
$$

where $H$ and $l$ are the height and the length of the bump and $v$ is vehicle forward speed. We choose $H=0.06 \mathrm{~m}, l=2 \mathrm{~m}$, and $v=3.6 \mathrm{~km} / \mathrm{h}$ in this paper. The road inputs to the front and rear wheels have same peak amplitude with a time delay of $(a+b) / v$ shown in Figure 13 .

In this case, the front and rear wheels inputs with a time delay are applied to excite the warp motion. Figure 14 shows the comparisons of dynamic tyre forces for the four wheels (fl, fr, rl, and rr) of the VKDS and VCS. The dynamic tyre force is proportional to the tyre deflection and is calculated 


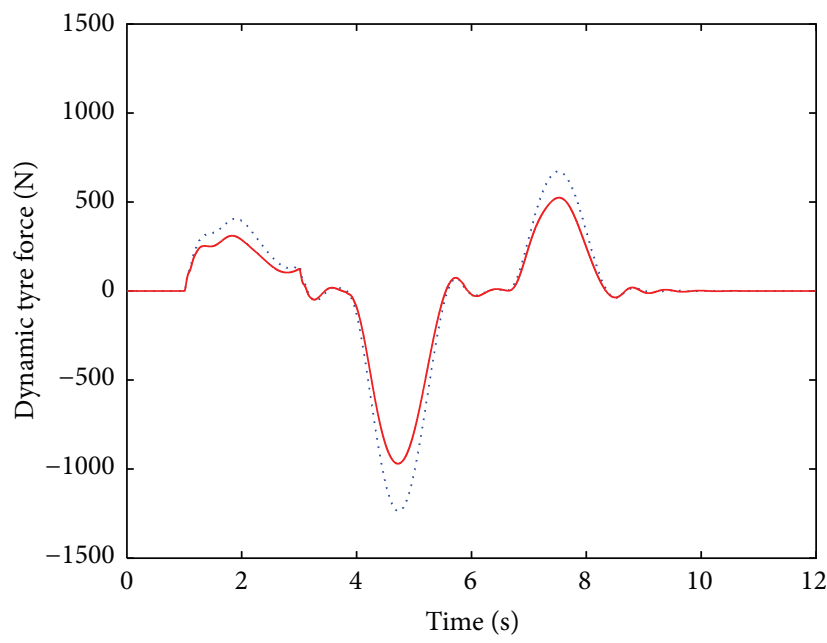

VCS

- VKDS

(a)

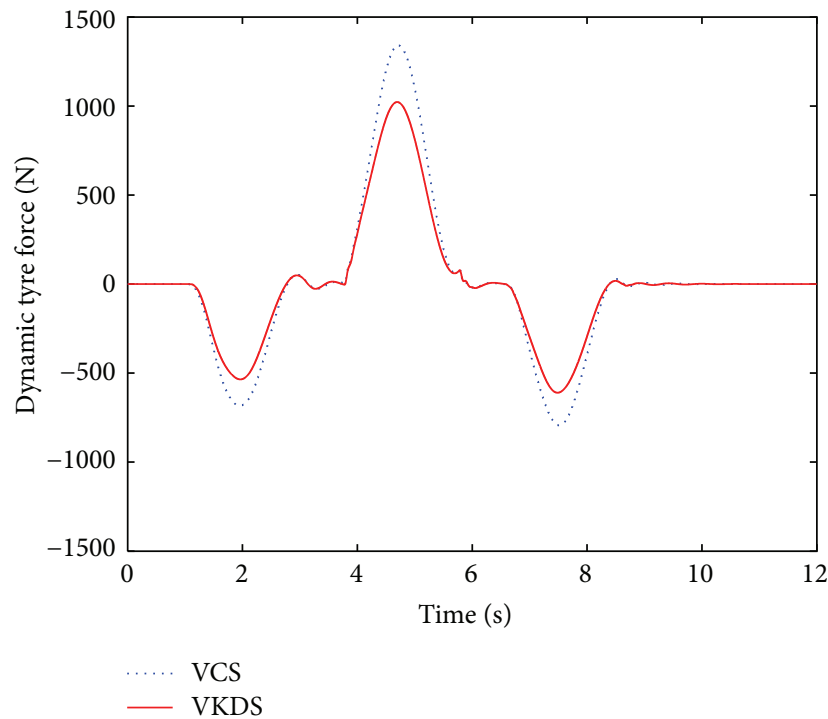

(c)

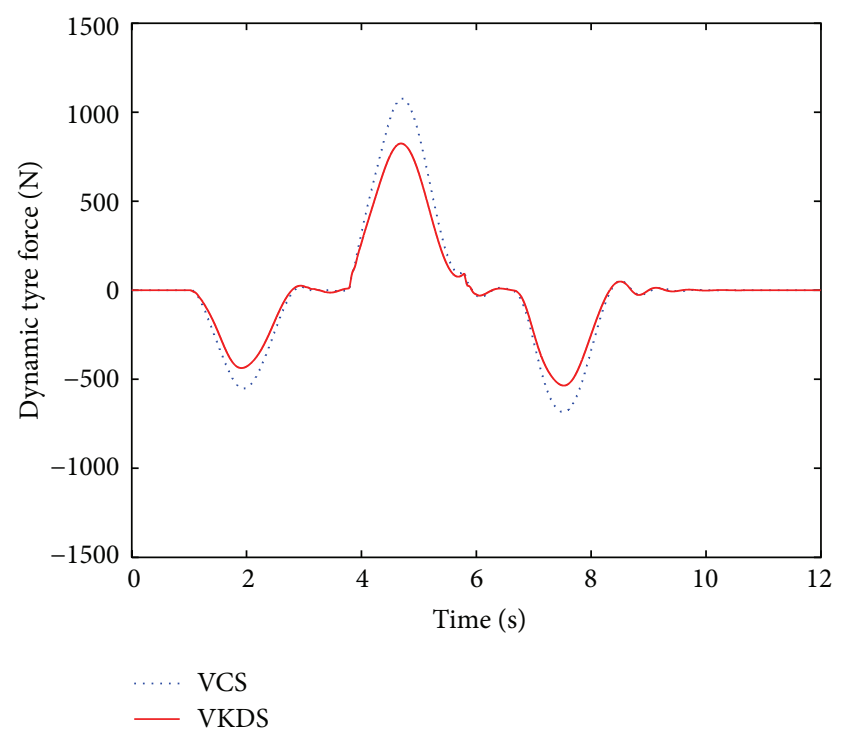

(b)

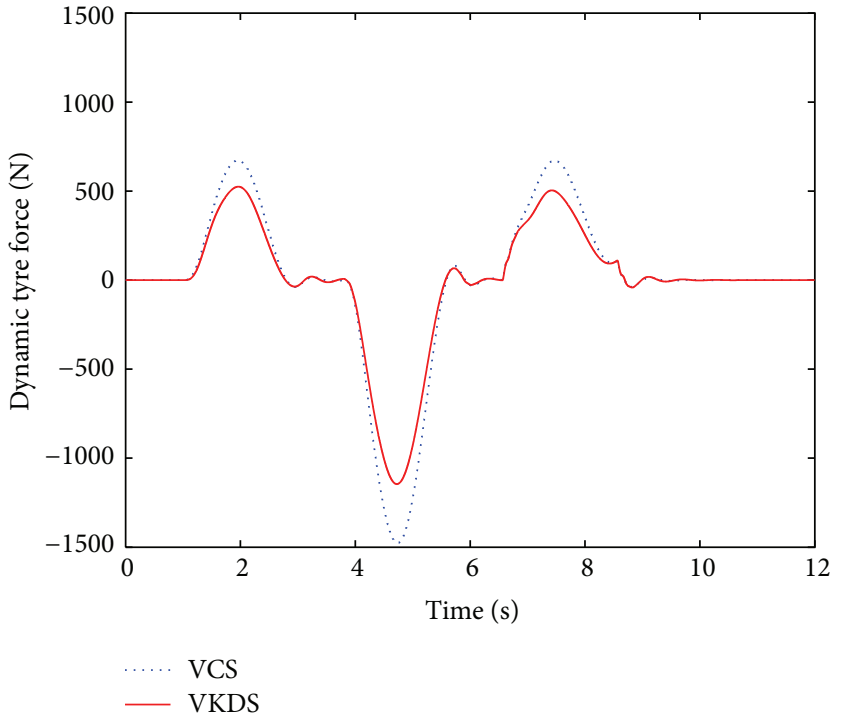

(d)

FIgure 14: (a) Dynamic tyre force of the VCS and VKDS in front left wheel. (b) In front right wheel. (c) In rear left wheel. (d) In rear right wheel.

as $k_{t i}\left(z_{g i}(t)-z_{u i}(t)\right)$ with the tyre stiffness $k_{t i}$. It can be seen from Figure 14 that the KDS system generates less tyre dynamic force than the conventional suspension system. As mentioned in Section 4, the KDS system is unable to restrict the suspension movement in the warp mode, which is beneficial to the contact between the wheels and the ground, but the conventional antiroll bar can limit the suspension movement due to the connection between the left and right wheels. It leads to the small fluctuation of the dynamic tyre force for the VKDS. Hence, the KDS system can improve ground holding performance.

5.2.3. Bounce Motion. The VKDS and VCS are evaluated for relative ride dynamic analysis under random road condition and different vehicle speeds. In order to reasonably evaluate vehicle ride comfort, the road surface spectrums that mainly consist of four random roads (smooth, medium-smooth, medium-rough, and rough roads) are applied in this set of simulations. The vertical displacement power spectral density (PSD) characteristics of the three road profiles at a forward speed of $90 \mathrm{~km} / \mathrm{h}$ are shown in Figures 15(a), 15(b), 15(c), and 15(d), which are defined as the road inputs of the four wheels for the dynamic analysis. Based on the displacement PSD characteristics of four wheels shown in Figure 15, these four wheels are described as the front left wheel (fl), the front right wheel (fr), the rear left wheel (rl), and the rear right wheel (rl). Similar displacement PSD characteristics of three roads can be found in the literature [31]. 


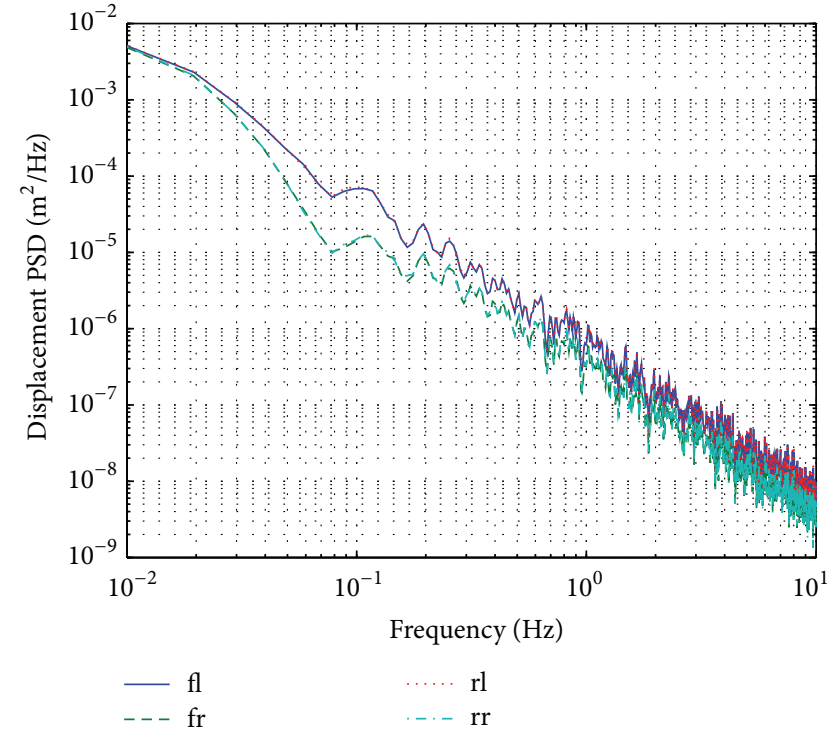

(a)

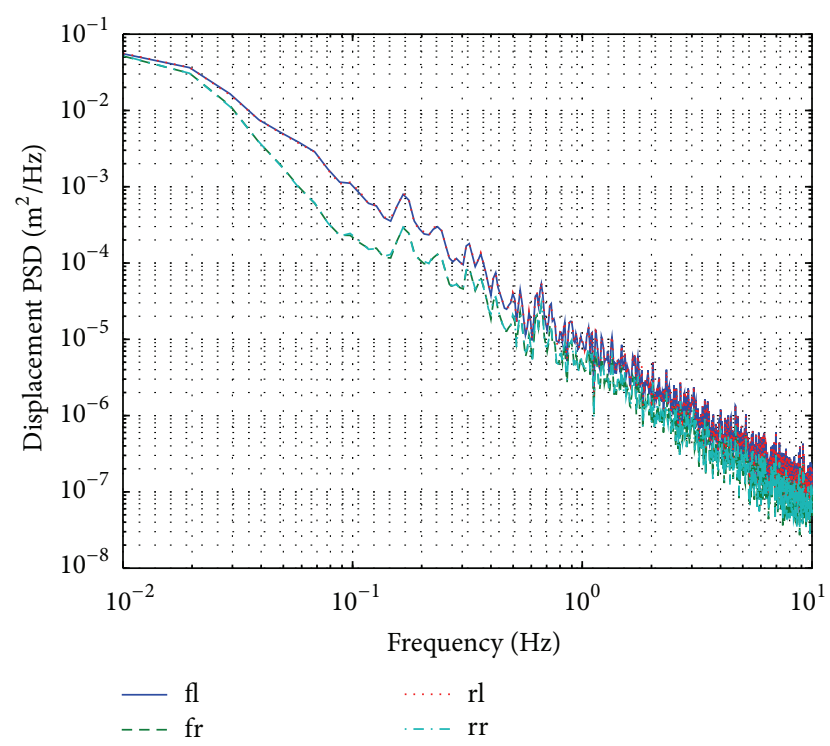

(c)

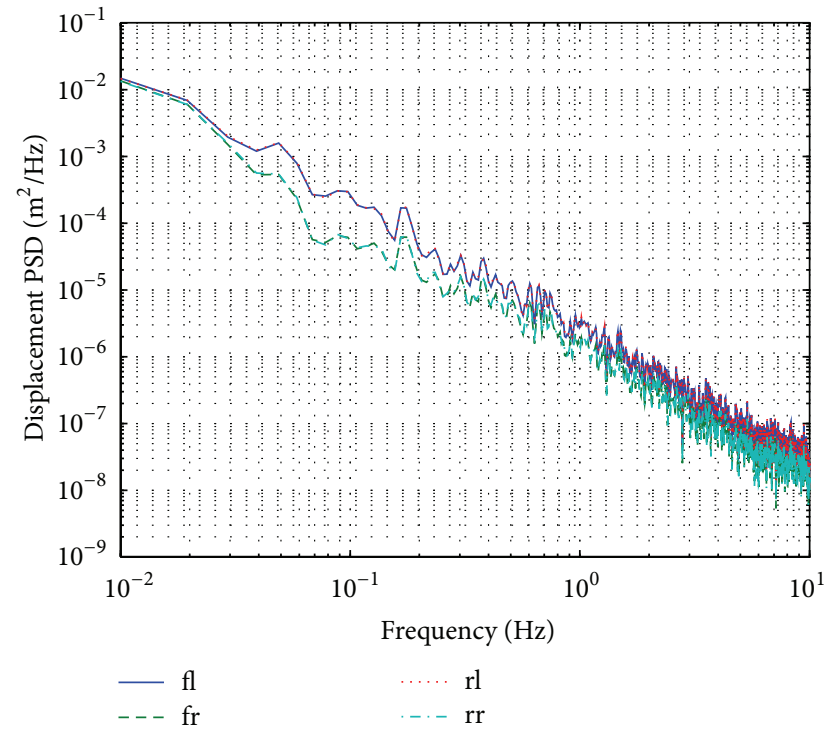

(b)

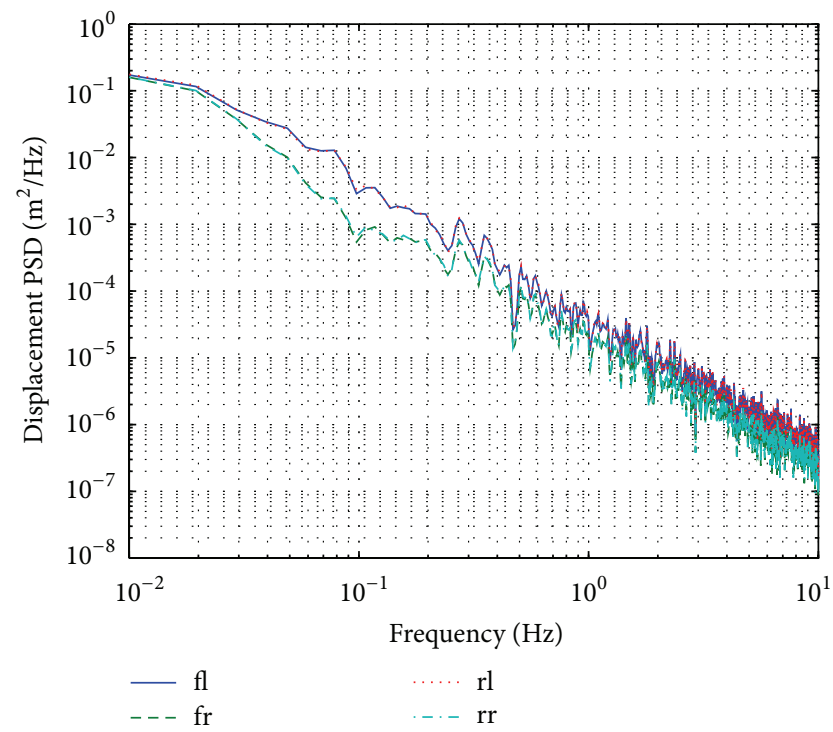

(d)

FIGURE 15: Vertical displacement temporal PSD characteristics of four road profiles at a speed of $90 \mathrm{~km} / \mathrm{h}$ : (a) Smooth. (b) Medium-smooth. (c) Medium-rough. (d) Rough.

Furthermore, the root mean square (RMS) vertical acceleration of vehicle body is used to quantify ride comfort. The frequency-weighted RMS acceleration levels of the human seat interface are defined as the evaluation of human perception of ride comfort according to ISO-2631-1 [32], but the unweighted RMS vertical acceleration response of the sprung mass can also assess the vehicle ride vibration in significant measure. Figures 16(a), 16(b), 16(c), and 16(d) illustrate the comparisons of RMS vertical acceleration of the sprung mass with VKDS and VCS under different vehicle speeds $(50,60$, 70,80 , and $90 \mathrm{~km} / \mathrm{h}$ ). The results show that the VKDS and VCS experience comparable RMS vertical acceleration of the sprung mass under most of road surfaces and different vehicle speeds. The comparable vertical ride responses of the VKDS and VCS are also verified from similar oscillation frequency of the bounce mode compared to the VCS (from $1.492 \mathrm{~Hz}$ to $1.493 \mathrm{~Hz}$ ) in Table 1. The results suggest that the KDS system does not provide the additional stiffness of bounce mode and has no negative effect on the vehicle ride comfort.

\section{Discussions and Future Work}

The study of this paper mainly focuses on the performance analysis of the newly proposed KDS system. According to the system description, the KDS system is installed on the conventional vehicle through the disconnected antiroll bars, so the basic physical parameters of the VCS and VKDS are the same. Because of the sameness, the characteristics 

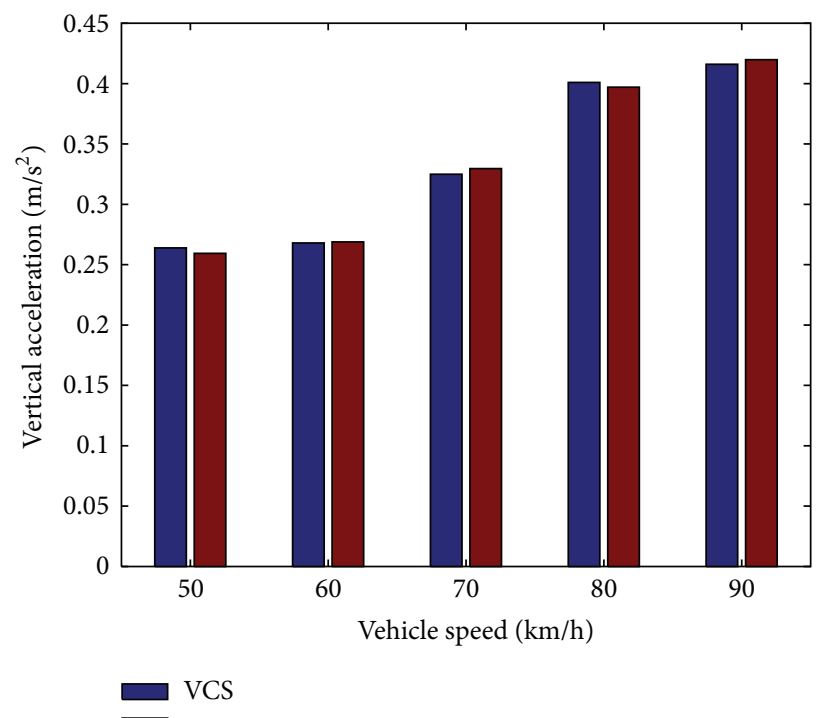

$\square$ VKDS

(a)

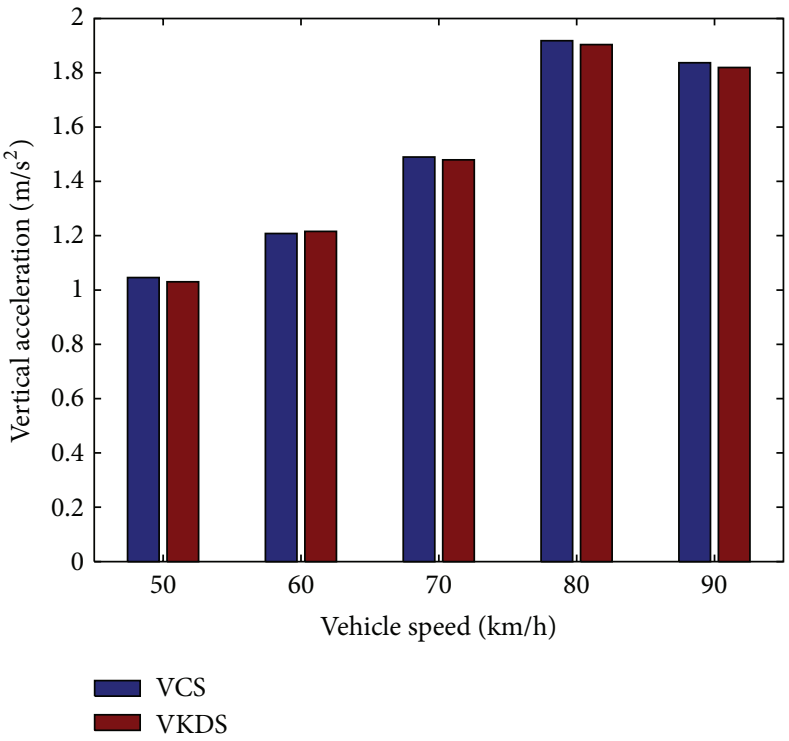

(c)

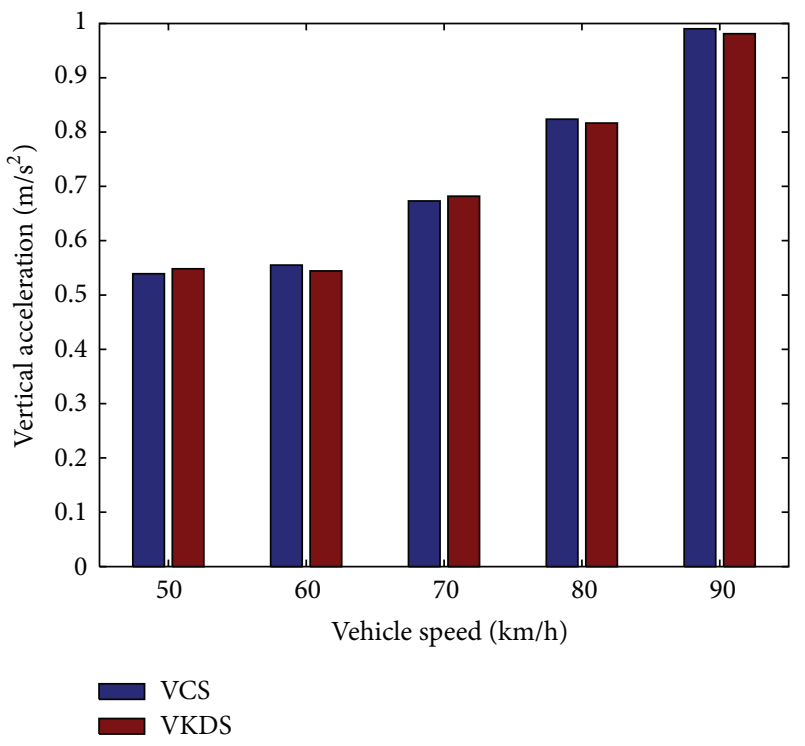

(b)

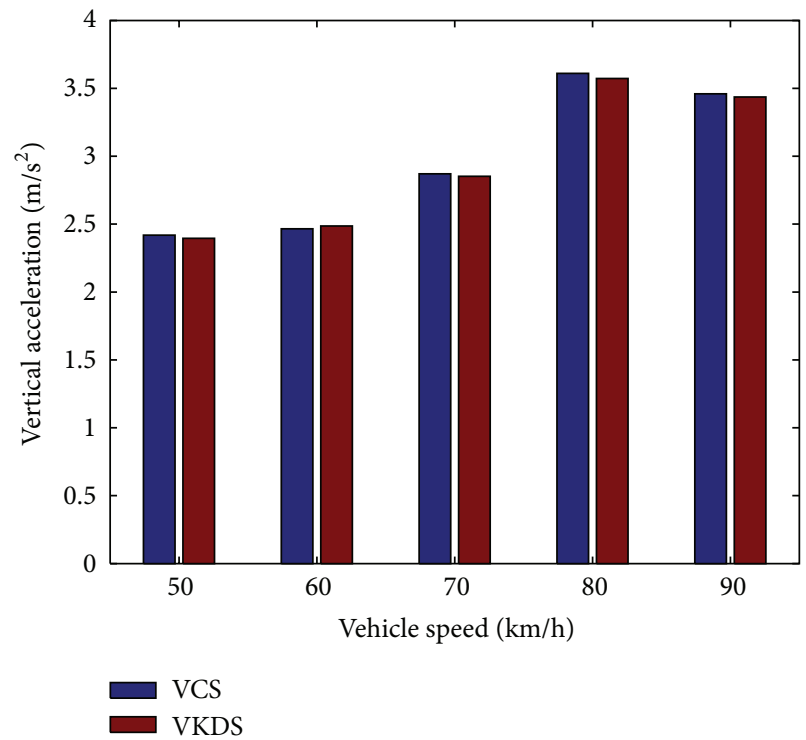

(d)

FIGURE 16: Comparisons of the sprung mass vertical ride responses of the VCS and VKDS: (a) smooth; (b) medium-smooth; (c) mediumrough; $(\mathrm{d})$ rough.

of the suspension system and tyre assembly are defined to be linear ones for simplifying the analysis of the KDS system. In addition, a linear suspension model may be applicable in some small-to-moderate amplitude applications [24]. Under general conditions, many light vehicles may not have the larger body roll angle and the longer suspension displacements for the roll motion. In warp motion, the vehicle is driven on the rough road at the lower velocity and the lower exaction frequency. Although the wheel and tyre assembly have the important role of attenuating high frequency vibrations, the dynamic characteristic of wheels may be assumed to be linear in lower frequency vibrations in order to analyze the vertical tyre dynamic force. Furthermore, in this paper, the frequency-dependent factors in the mechanical system, such as tyre damping, are neglected in the model without adding further complexity to the solution. Hrovat suggests that this full vehicle model generally predicts the acceleration response up to around 10 or $12 \mathrm{~Hz}$ on the rough road, with declining accuracy above that [33]. The hydraulic impedance method may be applicable for any conceivable analytical vehicle model in small amplitude applications, in which nonlinearities in the fluid system may be negligible [25]. Considering the above-mentioned reasons, the linear vehicle model is also introduced to analyze the modal characteristics of the VCS and VKDS.

Nevertheless, it can be seen that the most obvious limitation of the adopted analysis method is its linearity in this paper. In practical application, we often encounter many nonlinearities in the suspension hydraulic system and tyre assembly, such as conventional damper characteristics, 
the nonlinearities in the fluid system, and the nonlinear characteristics of wheels. Hence, an extension of the proposed methodology to a full nonlinear vehicle model needs to be considered in future works. This extension would be more applicable conceptually and would be essential for capturing dynamic response between all the vehicle rigid-body modes. Meanwhile, the experiment will be conducted to confirm the advantage of the KDS system. Mikhlin has used the nonlinear normal modes (NNMs) method to obtain the bounce motion property of a seven-DOF vehicle model with the front and rear springs of the nonlinear elastic characteristic [34]. Thus, nonlinear normal modes will be applied to analyze the modal property of the nonlinear vehicle model in future works, which can offer a solid theoretical and mathematical tool for interpreting a wide class of nonlinear modal phenomena. The other limitation is that the pitch motion has not been deeply explored in this paper. It can be seen that an adaptive vibration control strategy has been proposed for the nonlinear uncertain suspension systems to stabilize both the bounce and pitch motions of the car in the literature $[35,36]$. Based on these theories, the active control strategy would be considered as future works in order to improve ride comfort and control the pitch motion of the passive VKDS.

\section{Conclusions}

In this paper, a novel KDS system is proposed to improve vehicle roll and warp motion performance without affecting ride comfort. A multidisciplinary approach is applied to develop a hydromechanical coupled model for the vehicle with KDS system. The characteristics of the KDS-equipped vehicle about vehicle bounce, roll, and warp motions in the frequency domain and time domain are presented. The natural frequencies and modal shapes of the system have been obtained in the frequency domain, and the dynamic responses of the bounce, roll, and warp motions have been analyzed under various road excitations in time domain.

In order to illustrate the potential benefits of the proposed suspension, the comparison analysis of the vehicles equipped with the conventional suspension and the proposed KDS system has been carried out in this study. From the comparison, the results demonstrated that (1) the proposed KDS system could decouple the roll and warp modes, (2) the KDS system could provide higher roll stiffness to enhance handling performance, (3) the KDS system could reduce warp stiffness to improve wheels ground holding performance, and (4) the KDS system could hardly provide additional stiffness to bounce and pitch modes so that the VKDS has similar ride comfort as the VCS.

\section{Parameters}

(i) The Physical Parameters of a Seven-DOF Vehicle Model

$m_{s}:$ Vehicle sprung mass, $1558 \mathrm{~kg}$

$I_{x x}$ : Pitch moment inertia of the sprung mass, $2381 \mathrm{~kg} \cdot \mathrm{m}^{2}$

$I_{y y}:$ Roll moment inertia of the sprung mass, $600 \mathrm{~kg} \cdot \mathrm{m}^{2}$ a: $\quad$ Distance from the sprung mass CG to the front axle, $1.25 \mathrm{~m}$

$b$ : $\quad$ Distance from the sprung mass CG to the rear axle, $1.53 \mathrm{~m}$

$t_{f}$ : Half width of the front axle, $0.6 \mathrm{~m}$

$t_{r}$ : $\quad$ Half width of the rear axle, $0.5 \mathrm{~m}$

$m_{u f}: \quad$ Front unsprung masses, $96.4 \mathrm{~kg}$

$m_{u r}: \quad$ Rear unsprung masses, $105.6 \mathrm{~kg}$

$k_{s f}$ : Spring rate of the front suspension, $36.6 \mathrm{~N} / \mathrm{mm}$

$k_{s r}$ : Spring rate of the rear suspension, $42.7 \mathrm{~N} / \mathrm{mm}$

$c_{s f}$ : Damping coefficient of the front suspension, $3000 \mathrm{~N} * \mathrm{~m} / \mathrm{s}$

$c_{s r}$ : Damping coefficient of the rear suspension, $2700 \mathrm{~N} * \mathrm{~m} / \mathrm{s}$

$k_{t f} / k_{t r}$ : Vertical stiffness of tyres, $381 \mathrm{~N} / \mathrm{mm}$

$k_{\text {arbf }}$ : Front antiroll bar stiffness, $45 \mathrm{~N} / \mathrm{mm}$

$k_{\text {arbr }}$ : Rear antiroll bar stiffness, $8 \mathrm{~N} / \mathrm{mm}$.

\section{(ii) Hydraulic Parameters}

$\rho: \quad$ Hydraulic fluid density, $870 \mathrm{~kg} / \mathrm{m}^{3}$

E: Bulk modulus, $1400 \mathrm{MPa}$

$V_{p}$ : Accumulator precharge gas volume, $0.65 \mathrm{~L}$

$P_{p}$ : Accumulator precharge pressure, 20 bar

D: Diameter of cylinder piston, $0.05 \mathrm{~m}$

$d$ : Diameter of cylinder piston rod, $0.03 \mathrm{~m}$

$P_{0}$ : Mean system pressure, $40 \mathrm{bar}$.

\section{Competing Interests}

The authors declare that there are no competing interests regarding the publication of this article.

\section{Acknowledgments}

This work was supported by the National Natural Science Foundation of China (Grant no. 51175157) and the project of State Key Laboratory of Advanced Design and Manufacture for Vehicle Body (Grant no. 71575005). The authors wish to gratefully acknowledge the help of Professor Haiping Du in the final language editing of this paper.

\section{References}

[1] D. J. Cole, "Fundamental issues in suspension design for heavy road vehicles," Vehicle System Dynamics, vol. 35, no. 4-5, pp. 319360, 2001.

[2] R. S. Sharp and D. A. Crolla, "Road vehicle supsension system design-a review," Vehicle System Dynamics, vol. 16, no. 3, pp. 167-192, 1987.

[3] T. D. Gillespie, Fundamentals of Vehicle Dynamics, SAE, Warrendale, Pa, USA, 1992.

[4] R. W. Goldman, M. El-Gindy, and B. T. Kulakowski, "Rollover dynamics of road vehicles: literature survey," International Journal of Heavy Vehicle Systems, vol. 8, no. 2, pp. 103-141, 2001.

[5] M. C. Smith and G. W. Walker, "Interconnected vehicle suspension," Proceedings of the Institution of Mechanical Engineers, Part 
D: Journal of Automobile Engineering, vol. 219, no. 3, pp. 295307, 2005.

[6] J. Fontdecaba, "Integral suspension system for motor vehicles based on passive components," SAE Technical Paper 2002-013105, 2002.

[7] D. Cao, S. Rakheja, and C.-Y. Su, "Roll- and pitch-plane coupled hydro-pneumatic suspension-Part 1: feasibility analysis and suspension properties," Vehicle System Dynamics, vol. 48, no. 3, pp. 361-386, 2010.

[8] D. Cao, X. Song, and M. Ahmadian, "Editors' perspectives: road vehicle suspension design, dynamics, and control," Vehicle System Dynamics, vol. 49, no. 1-2, pp. 3-28, 2011.

[9] N. Docquier, A. Poncelet, M. Delannoy, and P. Fisette, "Multiphysics modelling of multibody systems: application to car semi-active suspensions," Vehicle System Dynamics, vol. 48, no. 12, pp. 1439-1460, 2010.

[10] R. A. Williams, "Automotive active suspensions part 2: practical considerations," Proceedings of the Institution of Mechanical Engineers, Part D: Journal of Automobile Engineering, vol. 211, no. 6, pp. 427-444, 1997.

[11] D. Alexander, "Mechanical advantage," in Automotive Engineering International, pp. 38-44, 2004.

[12] Tenneco Inc, "Company Website-Products and Technologies," Tenneco Inc., http://www.tenneco.com/OriginalEquipment/ RideControl/ProductsandTechnologies/.

[13] P. J. Liu, S. Rakheja, and A. K. W. Ahmed, "Properties of an interconnected hydro-pneumatic suspension system," Transactions of the Canadian Society for Mechanical Engineering, vol. 19, no. 4, pp. 383-396, 1995.

[14] A. E. Moulton and A. Best, "Hydragas suspension," SAE Technical Paper Series 790374, SAE International, 1979.

[15] M. Ortiz, "Principles of interconnected suspension: part2 methods of non-rigid interconnection and their effects," Race Car Engineering, vol. 7, pp. 56-59, 1997.

[16] E. Zapletal, "Balanced suspension," SAE Technical Paper Series SAE 2000-01-3572, 2000.

[17] N. Mace, Analysis and synthesis of passive interconnected vehicle suspensions [Ph.D. dissertation], University of Cambridge, Cambridge, UK, 2004.

[18] S. Y. Bhave, "Effect of connecting the front and rear air suspensions of a vehicle on the transmissibility of road undulation inputs," Vehicle System Dynamics, vol. 21, no. 1, pp. 225-245, 1992.

[19] J. R. Wilde, G. J. Heydinger, D. A. Guenther, T. Mallin, and A. M. Devenish, "Experimental evaluation of fishhook maneuver performance of a kinetic suspension system," SAE Technical Paper Series 2005-01-0392, SAE International, 2005.

[20] D. Cao, S. Rakheja, and C.-Y. Su, "Pitch plane analysis of a twingas-chamber strut suspension," Proceedings of the Institution of Mechanical Engineers, Part D: Journal of Automobile Engineering, vol. 222, no. 8, pp. 1313-1335, 2008.

[21] D. Cao, S. Rakheja, and C.-Y. Su, "Dynamic analyses of roll plane interconnected hydro-pneumatic suspension systems," International Journal of Vehicle Design, vol. 47, no. 1-4, pp. 51-80, 2008.

[22] N. Zhang, W. A. Smith, and J. Jeyakumaran, "Hydraulically interconnected vehicle suspension: background and modelling," Vehicle System Dynamics, vol. 48, no. 1, pp. 17-40, 2010.

[23] W. A. Smith, N. Zhang, and W. Hu, "Hydraulically interconnected vehicle suspension: handling performance," Vehicle System Dynamics, vol. 49, no. 1-2, pp. 87-106, 2011.
[24] W. A. Smith, An investigation into the dynamics of vehicles with hydraulically interconnected suspensions [Ph.D. thesis], University of Technology, Sydney, Australia, 2009.

[25] F. Ding, X. Han, Z. Luo, and N. Zhang, "Modelling and characteristic analysis of tri-Axle trucks with hydraulically interconnected suspensions," Vehicle System Dynamics, vol. 50, no. 12, pp. 1877-1904, 2012.

[26] C. B. Heyring and E. Bay, "Roll stabilization mechanisms in vehicular suspension systems," PCT, US6302417B1[P], 2001.

[27] Y. Hu, M. Z. Chen, and Z. Hou, "Multiplexed model predictive control for active vehicle suspensions," International Journal of Control, vol. 88, no. 2, pp. 347-363, 2015.

[28] M. Zheng, P. Peng, B. Zhang, N. Zhang, L. Wang, and Y. Chen, "A new physical parameter identification method for two-axis on-road vehicles: simulation and experiment," Shock and Vibration, vol. 2015, Article ID 191050, 9 pages, 2015.

[29] L. Wang, Motion-mode energy method and its implementation based on active hydraulically interconnected suspension [Ph.D. thesis], University of Technology, Sydney, Australia, 2013.

[30] D. Harty, "A review of dynamic intervention technologies and a method to choose between them," in Proceedings of the Vehicle Dynamics Expo 2005, Open Technology Forum, Stuttgart Messe, Stuttgart, Germany, May-June 2005.

[31] D. Cebon, Handbook of Vehicle-Road Interaction, Swets and Zeitlinger, Lisse, The Netherlands, 1999.

[32] ISO2631-1, Mechanical Vibration and Shock-Evaluation of Human Exposure to Whole-Body Vibration-Part1: General Requirements, ISO, Geneva, Switzerland, 1997.

[33] D. Hrovat, "Applications of optimal control to advanced automotive suspension design," Journal of Dynamic Systems, Measurement, and Control, vol. 46, no. 5, pp. 545-553, 1977.

[34] Y. V. Mikhlin, "Two formulations of nonlinear normal vibration modes and their applications," in Proceedings of the IUTAM Symposium on Nonlinear Dynamics for Advanced Technologies and Engineering Design, vol. 32, pp. 31-45, 2012.

[35] W. Sun, H. Gao, and O. Kaynak, "Adaptive backstepping control for active suspension systems with hard constraints," IEEE/ASME Transactions on Mechatronics, vol. 18, no. 3, pp. 1072-1079, 2013.

[36] W. Sun, H. Pan, and H. Gao, "Filter-based adaptive vibration control for active vehicle suspensions with electrohydraulic actuators," IEEE Transactions on Vehicular Technology, vol. 65, no. 6, pp. 4619-4626, 2016. 


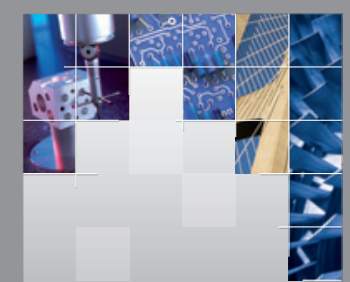

\section{Enfincering}
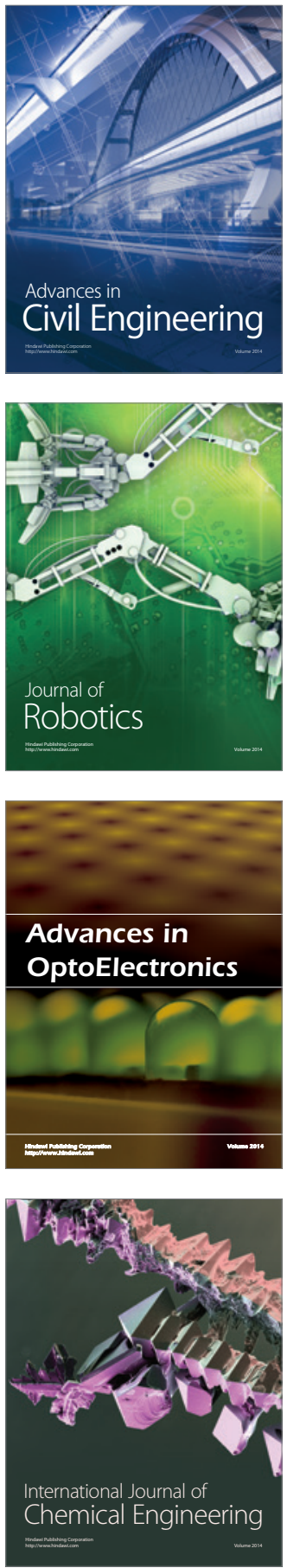

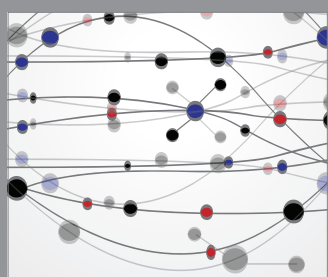

The Scientific World Journal

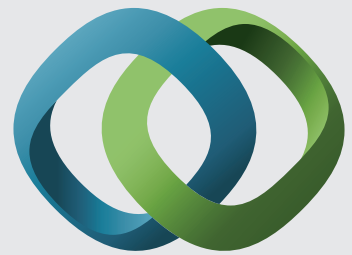

\section{Hindawi}

Submit your manuscripts at

http://www.hindawi.com
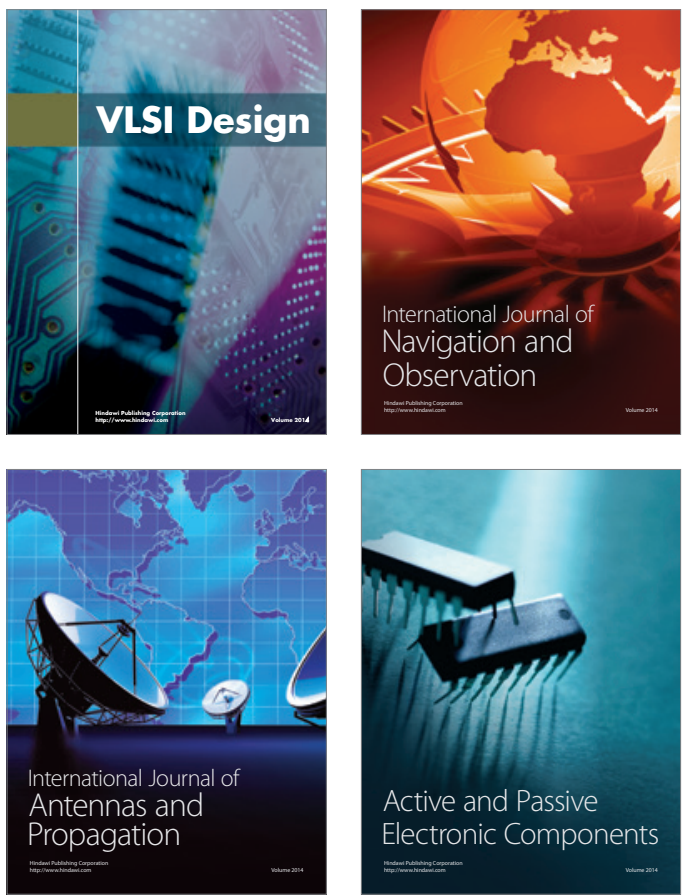
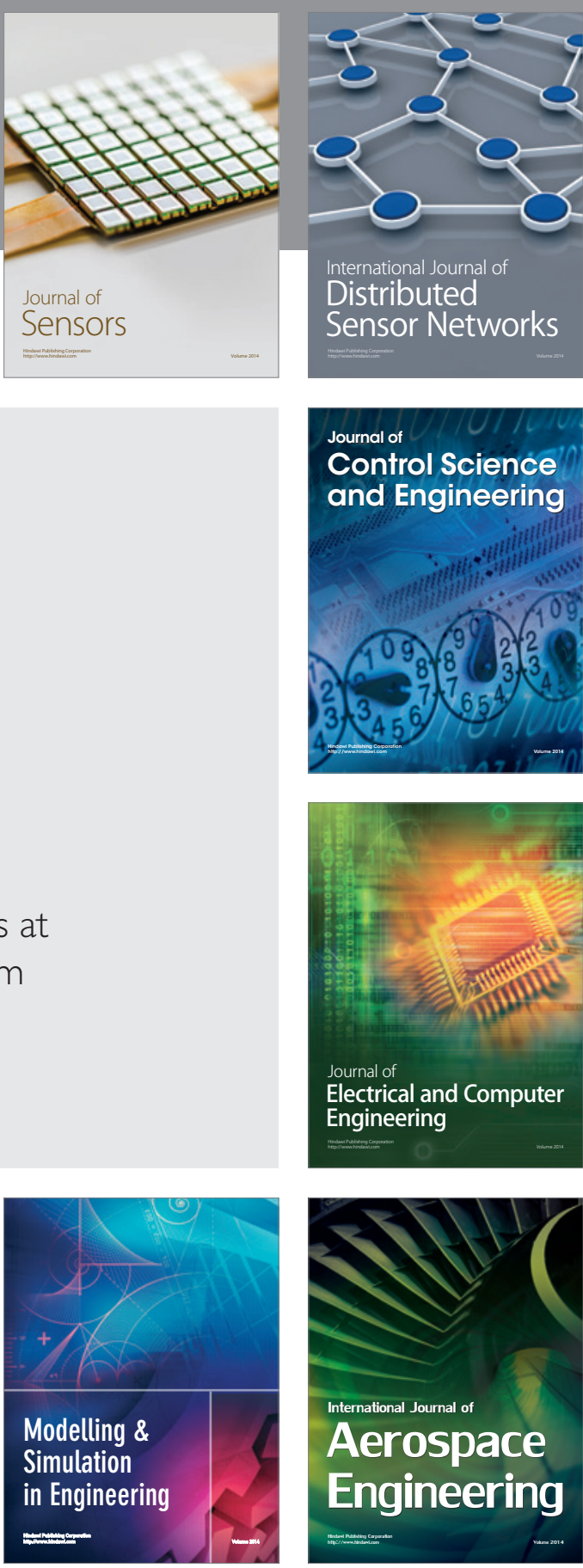

International Journal of

Distributed

Sensor Networks

Journal of

Control Science

and Engineering
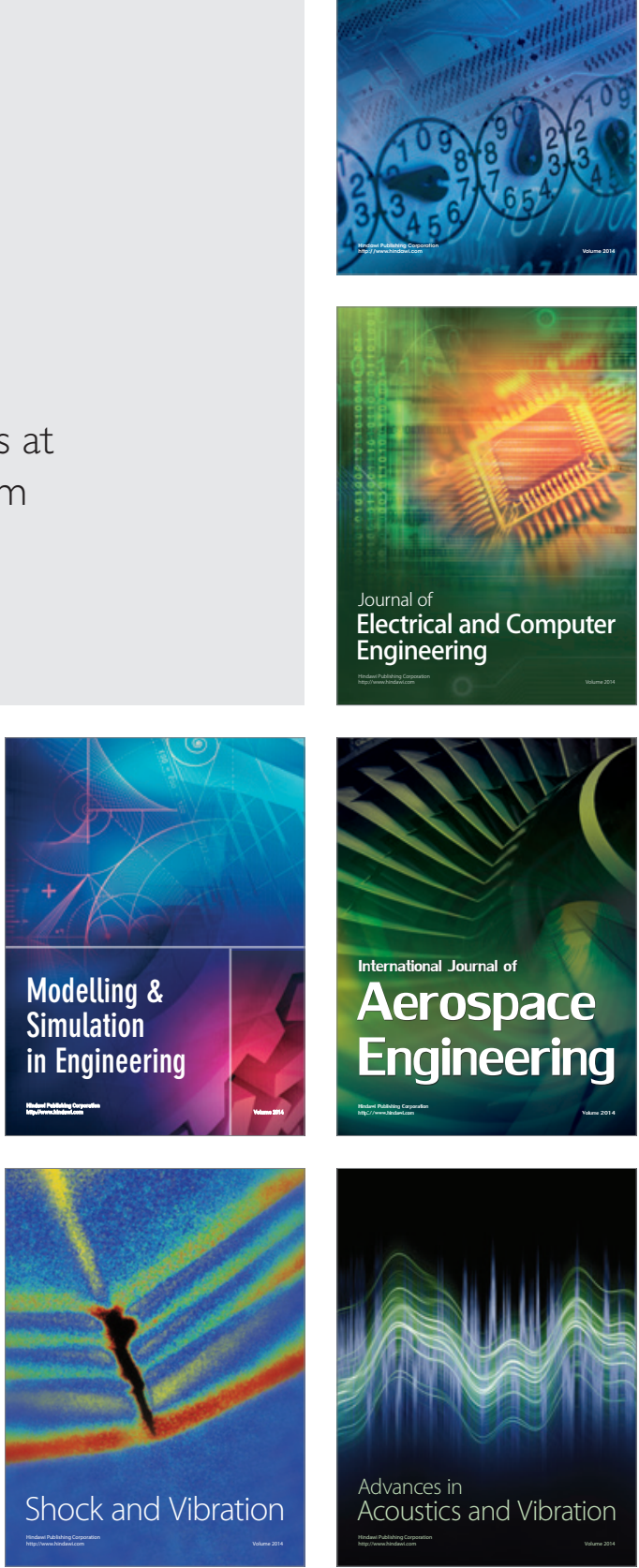